\title{
Analysis of protein glycosylation by mass spectrometry
}

\author{
Willy Morelle \& Jean-Claude Michalski \\ Unité Mixte de Recherche CNRS/USTL 8576, Glycobiologie Structurale et Fonctionnelle, IFR 147, Bâtiment C9, Université des Sciences et Technologies de Lille 1, \\ 59655 Villeneuve d'Ascq Cedex, France. Correspondence should be addressed to W.M. (willy.morelle@univ-lille1.fr).
}

Published online 21 June 2007; doi:10.1038/nprot.2007.227

\begin{abstract}
We present a detailed protocol for the structural analysis of protein-linked glycans. In this approach, appropriate for glycomics studies, $\mathrm{N}$-linked glycans are released using peptide $\mathrm{N}$-glycosidase $\mathrm{F}$ and $\mathbf{0}$-linked glycans are released by reductive alkaline $\beta$-elimination. Using strategies based on mass spectrometry (matrix-assisted laser desorption/ionization-time of flight mass spectrometry and nano-electrospray ionization mass spectrometry/mass spectrometry (nano-ESI-MS-MS)), chemical derivatization, sequential exoglycosidase digestions and linkage analysis, the structures of the $\mathrm{N}$ - and/or $\mathbf{0}$-glycans are defined. This approach can be used to study the glycosylation of isolated complex glycoproteins or of numerous glycoproteins encountered in a complex biological medium (cells, tissues and physiological fluids).
\end{abstract}

\section{INTRODUCTION}

Glycosylation is a common post-translational modification. There are two main types of protein glycosylation: N-glycosylation, in which the glycan is attached to an Asn residue present in the tripeptide consensus sequon Asn-X-Ser/Thr (where X can be any amino acid except Pro), and O-glycosylation, in which the glycan is attached to a Ser or Thr residue. Glycans are implicated in a wide range of intracellular, cell-cell and cell-matrix recognition events and are therefore of great biological interest ${ }^{1,2}$. To correlate functional features with defined structural parameters, detailed structural analyses of glycan chains are required. The most common manner of characterizing protein glycosylation involves the following steps: first, an enzymatic or chemical release of the attached glycans; second, derivatization of the released glycans via reductive amination with aromatic or aliphatic amines or permethylation; third, analysis of the glycans. The complete structural elucidation of glycans requires the determination of the sugar composition, sugar sequence, monosaccharide branching, interglycosidic linkages and anomeric configuration. In addition, glycoproteins may carry several different glycans, often a mixture of $\mathrm{N}$ - and $\mathrm{O}$-linked glycans, and these glycans may occur in variable amounts at glycosylation sites, with varying degrees of site occupancy. As a consequence, glycan analysis requires the sequential employment of several analytical techniques.

Here, we present the approach we use in our laboratory to study the $\mathrm{N}$ - and $\mathrm{O}$-glycan chains from native, recombinant glycoproteins or more complex biological samples such as unfractionated cellular extracts or physiological fluids. This approach is most appropriate for glycomics studies. $\mathrm{N}$-linked glycans are released using peptide $\mathrm{N}$-glycosidase $\mathrm{F}$ ( $\mathrm{PNGase} \mathrm{F}$ ) and $\mathrm{O}$-linked glycans are released from the $\mathrm{N}$-deglycosylated proteins/peptides by alkaline $\beta$-elimination. A portion of each pool of isolated $\mathrm{N}$ - and/or $\mathrm{O}$-glycans is derivatized by permethylation and the methylated derivatives are analyzed using matrix-assisted laser desorption/ ionization-time of flight mass spectrometry (MALDI-TOF-MS), by nano-electrospray ionization mass spectrometry/mass spectrometry (nano-ESI-MS-MS) and by linkage analysis before and after sequential exoglycosidase digestions. Partially methylated alditol acetates (PMAAs) are obtained from the permethylated samples for linkage analysis by gas chromatography (GC)-MS ${ }^{3}$. Structural assignments are based on molecular weight, fragment ion forma- tion (the latter derived from tandem MS (MS-MS) experiments) ${ }^{4}$, susceptibility to exoglycosidase digestions and linkage data ${ }^{3}$ (Fig. 1). This robust and highly sensitive mass spectrometric approach for characterizing the glycosylation pattern of proteins, cells, tissues and physiological fluids allows a rapid characterization of the glycoforms as well as their relative quantitation ${ }^{5-10}$.

\section{Release of glycans}

The differences in protein-sugar linkage chemistry of $\mathrm{N}$ - and $\mathrm{O}$ glycans require different approaches for the release of intact oligosaccharides. Several enzymes are available for releasing $\mathrm{N}$ glycans. The most popular is PNGase $\mathrm{F}^{11}$. PNGase F cleaves off the intact glycan as glycosylamine, which is readily converted to regular glycan. With few exceptions, PNGase F releases practically all protein-bound $\mathrm{N}$-linked carbohydrates except those with fucose attached to the third position of the Asn-linked GlcNAc residue ${ }^{12}$. Their corresponding glycoproteins are commonly found in plants and in nematodes. Such PNGase F-resistant glycans have been found to be sensitive to PNGase A, an enzyme found in almond emulsin. After releasing N-glycans using PNGase F, we use a chemical cleavage method for the release of O-glycans. Glycans linked O-glycosidically to Ser and Thr residues are released from the glycoproteins/glycopeptides in the reduced form containing GalNAc-ol by alkaline $\beta$-elimination in the presence of high concentrations of sodium borohydride $\left(\mathrm{NaBH}_{4}\right)$, which prevent 'peeling' of the released oligosaccharides by reducing each terminal GalNAc residue to its alditol ${ }^{13}$ (Fig. 2).

We use several methods to prepare $\mathrm{N}$-glycan samples with PNGase F (Fig. 1). The selection of these methods depends on the amount of glycoprotein available. If less than $50 \mu \mathrm{g}$ of protein is available (Step 1A), the protein should first be denatured by heating in the presence of SDS to increase the accessibility of PNGase F to the various glycosylation sites. To prevent the denaturation of PNGase F, a non-ionic detergent (nonidet P40, NP40) is added before digestion with the deglycosylation enzyme. After PNGase F digestion, the $\mathrm{N}$-deglycosylated protein is precipitated and the $\mathrm{N}$-glycans are purified using a Sep-Pak $\mathrm{C}_{18}$ cartridge to remove the detergents, which may considerably affect the quality of the MS spectra. With less than $50 \mu \mathrm{g}$ of protein, sequential MALDI profiling, MS-MS sequencing, linkage analysis and exoglycosidase 
digestions on the MALDI target can normally be performed. If more than $50 \mu \mathrm{g}$ of protein is available (Step 1B), we use another method, which does not require the presence of SDS for the denaturation of proteins. However, the throughput of this protocol is lower. In this method, to facilitate the release of $\mathrm{N}$-glycans without resorting to detergent denaturation, glycoproteins are first reduced and carboxamidomethylated. Reduced and carboxamidomethylated glycoproteins are then submitted to a proteolytic digestion to generate small peptides and glycopeptides before PNGase F digestion. PNGase Freleased glycans are then separated from peptides and O-glycopeptides using a SepPak $\mathrm{C}_{18}$ cartridge. Step $1 \mathrm{~B}$ is particularly appropriate for the analysis of glycans released from cells and tissues. In this case, approximately 10 million cells and several milligrams of tissues are necessary to perform MALDI profiling, MS-MS sequencing and linkage analysis. If glycoproteins are gel separated, then choose Step $1 \mathrm{C}^{14,15}$. In this case, MALDI profiling and MS-MS sequencing can be performed. Exoglycosidase digestions need to be carried out on the MALDI target (Step 18).

$\mathrm{O}$-glycans are released from the $\mathrm{N}$-deglycosylated protein (Step 1A) or O-glycopeptides (Step 1B) by reductive elimination and desalted through a Dowex $50 \times 8\left(\mathrm{H}^{+}\right.$ form). This method has worked well in our hands. Other methods, including gel reductive $\beta$-elimination, have been described ${ }^{16-19}$.

After PNGase F digestion, an aliquot (typically 50\%) of released glycans is subjected to sequential exoglycosidase digestions (Step 18) monitored by MALDITOF-MS and linkage analysis. After each exoglycosidase digestion, an aliquot is permethylated and analyzed by MALDI-TOFMS and linkage analysis. Another aliquot (typically 20\%) of released glycans is permethylated directly (Step 19) and the methylated derivatives are characterized by MALDI-TOF-MS, nano-ESI-MS-MS and linkage analysis. If PNGase F-released glycans are isolated from gel-separated proteins, exoglycosidase digestions are carried out on the MALDI target ${ }^{5,9,10,20}$.

\section{Mass spectrometry and permethylation}

Electrospray ionization (ESI) and MALDI MS play a crucial role in the characterization of glycosylation ${ }^{21,22}$. MALDI-TOFMS offers a simple means for screening complex mixtures, and MS-MS methods using electrospray with low-energy collisioninduced dissociation (CID) are valuable tools for the production

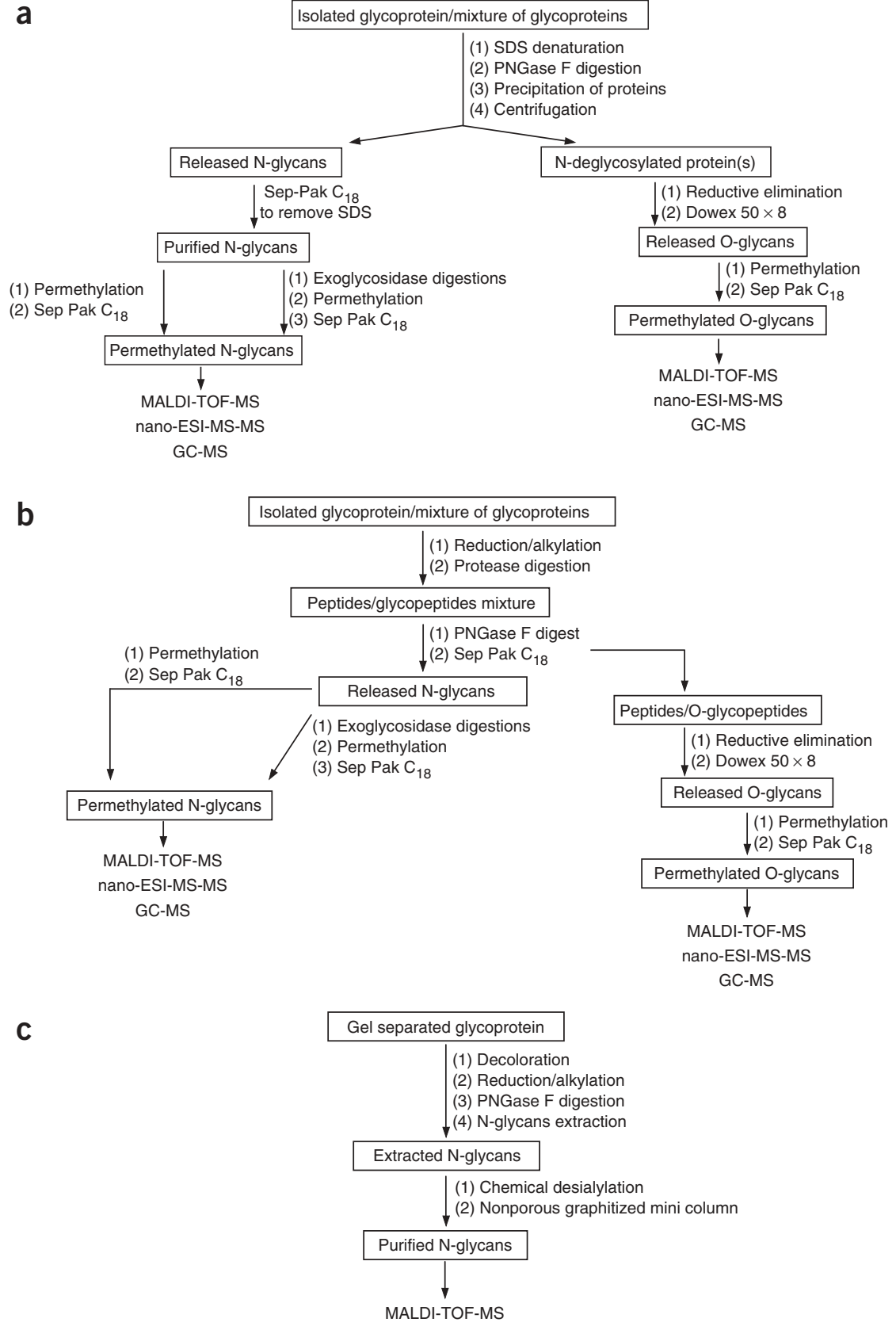

Figure 1 | Strategy for the determination of the structures of the $\mathrm{N}$ - and 0 -linked glycans of glycoproteins using mass spectrometry. The strategies in glycoprotein analysis depend on the amount of available sample. Several methods for preparing $\mathrm{N}$-glycans are described. If less than $50 \mu \mathrm{g}$ of protein is available, choose steps in panel a. After peptide N-glycosidase F (PNGase F) digestion, if you are not interested studying the 0-glycans of the proteins, you can proceed directly to the purification of the $\mathrm{N}$-glycans using a non-porous graphitized carbon column (Step 2A). If more than $50 \mu \mathrm{g}$ of protein is available, we use another method (steps in panel $\mathbf{b}$ ), which does not require the presence of SDS for the denaturation of proteins. For gel-separated glycoproteins, choose steps in panel $\mathbf{c}$.

of fragment ions to investigate the sequence and even linkage of glycans.

MALDI-TOF-MS is very often used as a first step because it is unique in its capacity to generate rapidly information about the nature and diversity of glycans released from native, recombinant glycoproteins or even more complex biological samples. Neutral glycans yield intense signals in the positive ion mode corresponding to sodium-cationized molecular species $[\mathrm{M}+\mathrm{Na}]^{+}$. This ion is 
often accompanied by a weaker $[\mathrm{M}+\mathrm{K}]^{+}$ion. Sialylated glycans are usually more difficult to analyze using MALDI-TOF-MS and give a mixture of ions such as $[\mathrm{M}+\mathrm{Na}]^{+},[\mathrm{M}+\mathrm{K}]^{+},[\mathrm{M}-n \mathrm{H}+$ $(n+1) \mathrm{Na}]^{+}$and $[\mathrm{M}-n \mathrm{H}+(n+1) \mathrm{K}]^{+}$. Furthermore, sialylated glycans can very easily lose a significant amount of sialic acid in the ion source or after the ion extraction from the ion source, considerably distorting the glycan profiles. To reduce this loss, sialylated glycans can be analyzed with TOF instruments in the linear negative ion mode. Neutral glycans are not, however, detected in the negative ion mode. In addition, the fragment ions formed within the ion source are still observed in the MALDI-TOF-MS spectrum. Several methods of derivatization to improve the stability of sialic acid residues by neutralizing their negative charge are currently in use. Methylesterification of the carboxyl group of sialic acid residues by reaction of their sodium salts with methyl iodide allows simultaneous analysis of neutral and sialylated oligosaccharides in the positive ion mode ${ }^{23}$. Permethylation of glycans using the method described by Ciucanu and Kerek also stabilizes the sialic acid residues ${ }^{24}$. Several recent modifications to this method have substantially improved its efficiency ${ }^{25,26}$.

In our lab, we have chosen to stabilize sialylated oligosaccharides using permethylation, which is by far the most important type of derivatization used in glycan MS. Despite the drawback of involving an additional wet chemistry step, permethylation derivatization offers several advantages: (i) sample clean-up using lipophilic extraction makes it possible to remove salts very easily; (ii) this derivatization significantly improves the sensitivity of detection of molecular ions; (iii) it allows simultaneous analysis of neutral and sialylated oligosaccharides in the positive ion mode; (iv) this approach also leads to predictable fragmentations that give characteristic 'maps' of fragment ions at each amino sugar residue; (v) furthermore, the methylation approach can be used for the elucidation of all interglycosidic linkages since GC/MS analysis of chemically modified monosaccharides that are derived from methylation, hydrolysis, reduction and acetylation of glycans can be performed after MALDI-TOF-MS analysis of permethylated glycans.

Since glycan moieties are composed of a relatively small number of different monosaccharide constituents with unique incremental masses, profiling of permethylated glycan structures using MALDITOF-MS allows us rapidly to obtain information about the nature and diversity of structures of glycans present. In addition, as the signal strength of permethylated glycans appears to reflect accurately the amount of material on the target, we are able to determine the relative quantities of each neutral and sialylated glycan present in a mixture by MALDI-TOF-MS permethylated glycan profiling. The mass of a molecular ion is calculated by adding the mass of a methyl group corresponding to the nonreducing end of the molecule and the mass of the group corresponding to the reducing end of the molecule to the sum of the increment masses of the sugar residues constituting the molecular ion. For non-reduced glycans (PNGase F-released N-glycans), the group corresponding to the reducing end of the molecule is a methyl-glycoside $\left(\mathrm{CH}_{3} \mathrm{O}\right)$ with a sodium to give the charge. For reduced glycans (O-glycans released using reductive elimination), the group corresponding to the reducing end of the molecule has the formula $\mathrm{C}_{2} \mathrm{H}_{7} \mathrm{O}$ with a sodium to give the charge. These are illustrated in Figure 3. Table 1 gives the accurate and average values
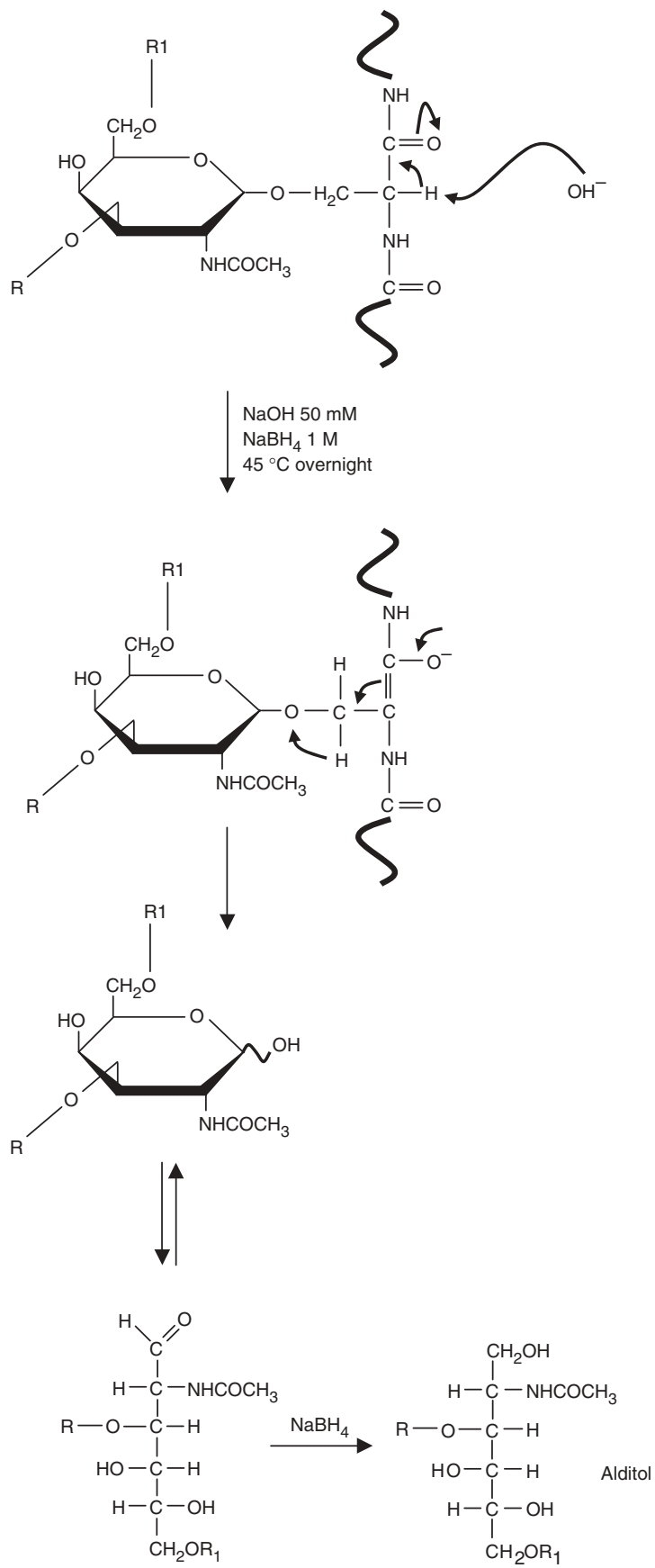

Figure 2 | Reaction steps for reductive elimination of 0-linked glycans. R, 3-linked saccharide; R1, 6-linked saccharide.

necessary to interpret MALDI-TOF-MS spectra of permethylated $\mathrm{N}$ - and O-glycans.

The permethylated components observed in the MALDI-TOFMS spectrum can be further analyzed using a nano-electrospray quadrupole TOF (Q-TOF)-MS to assist sequence assignment ${ }^{27,28}$. This instrument is used to obtain fragmentation spectra in a short time with high mass accuracy that reveal detailed structural and in some cases linkage information on complex oligosaccharides. Fragmentation of carbohydrates is dependent on several factors, such as the type of ion formation, its charge state and the energy deposited into the ion ${ }^{29,30}$. Two major types of ions are usually observed: glycosidic cleavages where bond rupture occurs between 
the sugar rings and involves a hydrogen migration, and cross-ring cleavages that involve the rupture of two bonds on the same sugar residue. The nomenclature generally used for describing these fragment ions is that proposed by Domon and Costello ${ }^{31}$. In this nomenclature, ions retaining the charge on the non-reducing terminus are named $\mathrm{A}, \mathrm{B}$ and $\mathrm{C}$, whereas the ions retaining charge on the reducing terminus are $\mathrm{X}, \mathrm{Y}$ and $\mathrm{Z}$ (Fig. 4). $\mathrm{A}$ and $\mathrm{X}$ correspond to cross-ring cleavages, whereas B, C, Y and Z correspond to glycosidic cleavages. Subscript numbers denote the cleavage position, starting at the reducing terminus for the $\mathrm{X}, \mathrm{Y}$ and $\mathrm{Z}$ ions, and at the non-reducing terminus for the others. In the case of ring cleavages, superscript numbers are given to show the cleaved bonds. Permethylated glycans usually yield intense sodium-cationized and protonated molecular species when analyzed in the ESI mode. The main fragmentation process of sodium-cationized species involves the cleavage of glycosidic bonds and gives rise to pertinent data on sequence and branching ${ }^{4,27,28}$. Under low-energy CID conditions, protonated species, significantly more labile than the corresponding sodium adducts, yield very simple fragmentation patterns, allowing immediate and unambiguous assignment of sequence and branching information and even information on some interglycosidic linkages ${ }^{28,32}$. Fragmentation of the permethylated glycans gave predominantly B-type glycosidic fragments. Y-type glycosidic fragments are also observed (Fig. 5). B-type ions result primarily from cleavage of the glycosidic bond at the $\mathrm{N}$-acetylhexosamine moiety with localization of the charge on the non-reducing end. These fragment ions are extremely helpful for antennae sequence assignments. The mass of these fragments is calculated by adding the non-reducing end increment (Table 1) with the sodium minus hydrogen to the sum of the residue masses. The most commonly encountered B-type ions from sodiated permethylated glycans are listed in Table 2 .

\section{Exoglycosidase digestions}

To define the monosaccharides and their anomeric configurations, and to confirm tentative sequences, additional experiments are required, and glycans can be treated with exoglycosidases. Exoglycosidases remove monosaccharides from the non-reducing termini of glycan chains. These enzymes are specific to the stereochemistry,

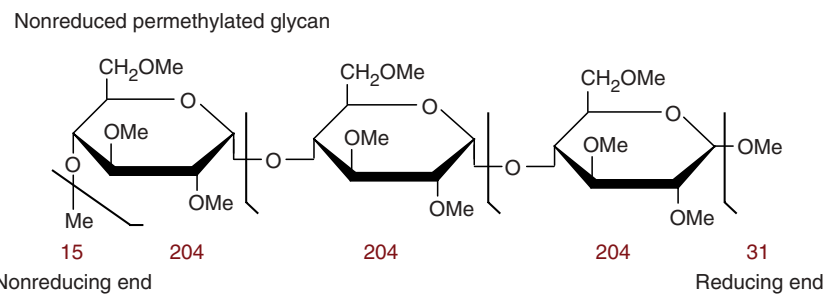

Reduced permethylated glycan

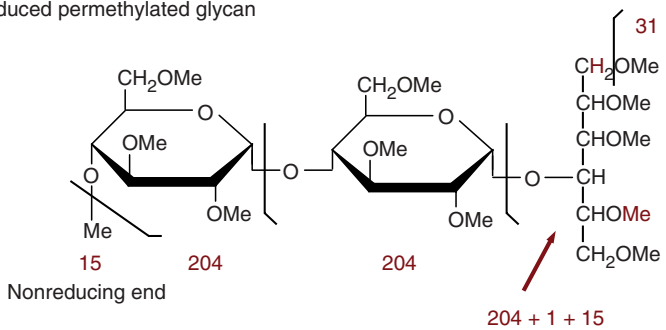

Figure 3 | Schematic representation showing the groups corresponding to the reducing end for non-reduced and reduced glycans.

the anomeric configuration of the monosaccharide being released and its linkage site with respect to the remainder of the glycan chain $^{33}$. A non-exhaustive list of commonly used exoglycosidases and the conditions to perform the digests is given in Table 3. It is recommended that highly specific exoglycosidases are used. PNGase F-released N-glycans are usually subjected to treatment with $\alpha$-sialidase, followed by $\beta$-galactosidase, $\beta$ - $N$-acetylhexosaminidase, $\alpha$-fucosidase and $\alpha$-mannosidase digestion. After enzymatic treatment, the mixture is analyzed by MALDI-TOF-MS to determine the number of monosaccharides released by the enzyme. Using several well-defined enzymes in sequence, the molecular mass information after each digestion step thus reveals the sequence of the monosaccharide constituents of the glycan chains ${ }^{20,34,35}$. These treatments can be applicable both to mixtures of glycans and to a specific glycan. If the treatment is performed on a mixture of glycans, the relative abundance of each ion obtained on the MALDI-TOF-MS spectrum should be taken into account in interpreting the exoglycosidase results.

Exoglycosidase digestions are performed in buffered solutions; consequently, a sample clean-up procedure is required before the

TABLE 1 | Residue masses of common monosaccharides and terminal groups.

\begin{tabular}{|c|c|c|c|c|}
\hline & \multicolumn{2}{|c|}{ Native } & \multicolumn{2}{|c|}{ Permethylated } \\
\hline \multicolumn{5}{|l|}{ Monosaccharides } \\
\hline Deoxyhexose & 146.0579 & 146.1430 & 174.0892 & 174.1968 \\
\hline Hexose & 162.0528 & 162.1424 & 204.0998 & 204.2230 \\
\hline $\mathrm{N}$-acetylhexosamine & 203.0794 & 203.1950 & 245.1263 & 245.2756 \\
\hline $\mathrm{N}$-glycolyl-neuraminic acid & 307.0903 & 307.2573 & 391.1842 & 391.4186 \\
\hline \multicolumn{5}{|l|}{ Terminal groups } \\
\hline Non-reducing end & 1.0078 & 1.0079 & 15.0235 & 15.0348 \\
\hline Reducing end & 17.0027 & 17.0073 & 31.0184 & 31.0342 \\
\hline Reduced reducing end & 19.0184 & 19.0232 & 47.0497 & 47.0770 \\
\hline
\end{tabular}


MALDI-TOF-MS analysis. Aliquots are taken after each digestion, permethylated and examined by MALDI-TOF-MS and linkage analysis after reverse-phase SepPak $\mathrm{C}_{18}$ purification. Sep-Pak $\mathrm{C}_{18}$ is a simple, rapid method for separating permethylated glycans from the remaining salts. Comparison of linkage data before and after exoglycosidase treatment makes it possible to establish where the removed monosaccharides were attached. If linkage analysis is not necessary, an aliquot taken after each digestion can be purified using a miniaturized porous graphitized carbon solid-phase extraction method and analyzed without derivatization by MALDI-TOF-MS after first removing sialic acids.

\section{Linkage analysis}

Even if the oligosaccharides are analyzed as mixtures, data from linkage analysis allow important structural conclusions to be drawn and can be used to confirm MALDI-TOF-MS and nano-electrospray Q-TOF-MS data. For example, linkage data can yield information on (i) the different classes of $\mathrm{N}$-glycans (high mannose structures, hybrid-type structures and complex-type structures) (Fig. 6); (ii) the different types of non-reducing sugars; (iii) the abundance of biantennary, triantennary and/or tetraantennary (Fig. 6) complex-type glycans in the N-glycan mixtures by comparing levels of 2-linked Man with 2,4-linked Man and 2,6-linked Man; (iv) the abundance of bisected structures with the 3,4,6-linked Man level; (v) the different types of antennae in complex-type glycans; (vi) the presence of core fucosylated structures.

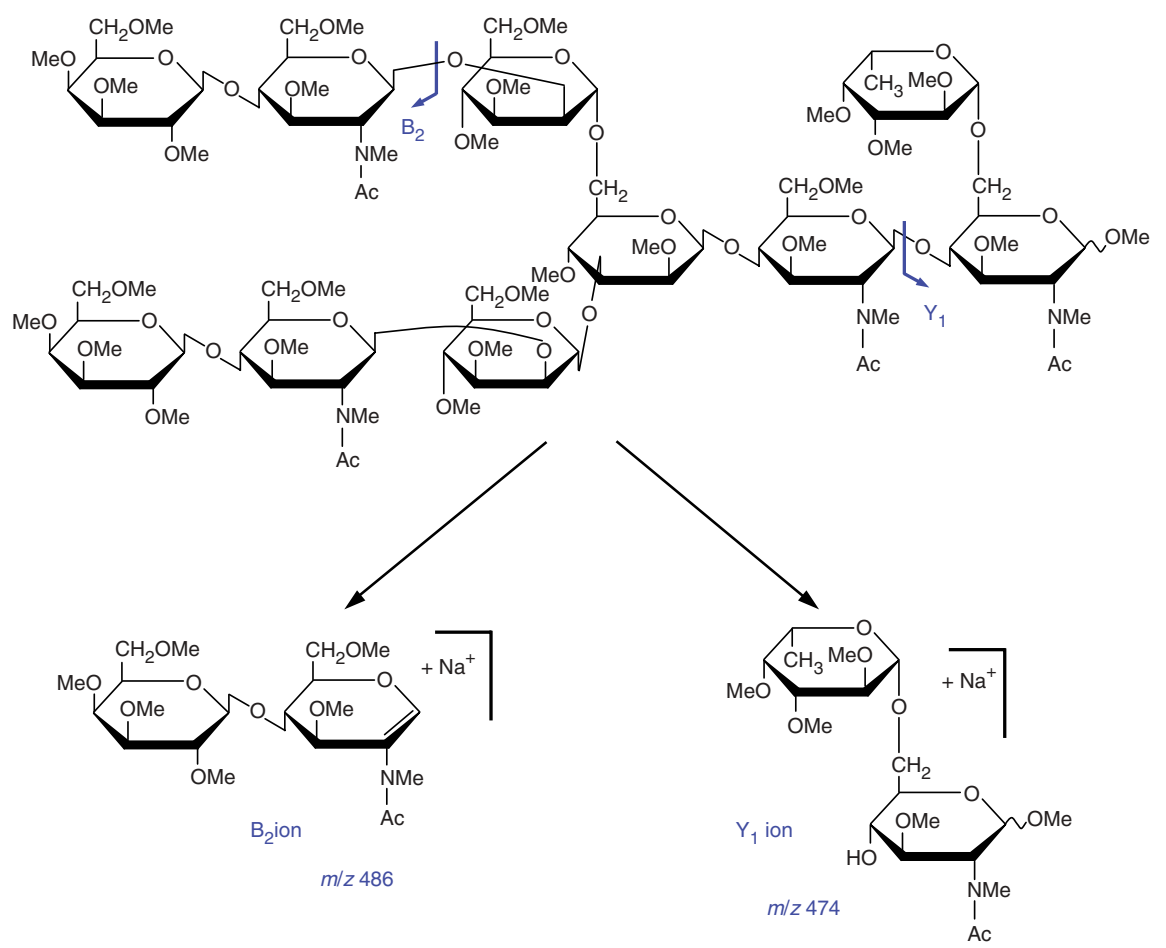

Figure 5 | Fragmentation of sodiated permethylated glycans by cleavage of the glycosidic bonds.
After MALDI-TOF-MS analysis, permethylated glycans are acid-hydrolyzed, deuteroreduced, and peracetylated. The resulting PMAAs are analyzed by electron impact-GC-MS (EI-GC-MS) ${ }^{36-38}$. The retention time on the capillary GC column and the fragment ions observed in the EI-MS spectra are used to identify the different types of residues. The position of the O-acetyl and O-methyl groups on the PMAA reflects the ring form and linkage positions of the glycosyl residue in the original glycan. The retention times and the characteristic fragment ions of several PMAAs are given in Table 4. Although retention times are specific to a user's lab, the order of elution of the compounds will be identical in another laboratory provided that similar columns are used. However, users need to prepare a collection of PMAA standards to establish their own lists of retention times. PMAAs are characterized by simple fragmentation patterns. The $m / z$ of the ions identifies the number of methoxylated and acetoxylated carbons in the fragment ions. The primary fragments derived from partially methylated hexitol acetate are formed by addition of methoxylated carbons, $44 \mathrm{U}$, and/or acetoxylated carbons, $72 \mathrm{U}$. Consequently, the fragment ions containing C-6 give $\mathrm{m} / \mathrm{z}$ values fitting the equation $(\mathrm{a} \times 44+\mathrm{b} \times$ $72+1)$ and the fragment ions containing $\mathrm{C}$ 1 give $m / z$ values fitting the equation $(\mathrm{a} \times$ $44+\mathrm{b} \times 72+2$ ). For a 6-deoxy sugar, the fragment ions containing C-6 give $\mathrm{m} / \mathrm{z}$ values fitting the formula $(\mathrm{a} \times 44+\mathrm{b} \times$ $72+15$ ) (ref. 38).

In addition, aminitol derivatives are readily identified by the fragment ion that carries the N-methylacetamidylated carbon and contributes $85 \mathrm{U}$ to the fragment ion ${ }^{38}$. Figure 7 illustrates the primary fragments obtained in EI-MS of several PMAAs, which are very useful in interpreting data. It is important to note that the sensitivity of this method is much lower than that of MALDITOF-MS or nano-electrospray Q-TOF-MS. Several micrograms of permethylated glycans are required for a satisfactory analysis.

\section{Present limitations}

In this glycomics approach, N-glycans are released using PNGase F. The mechanism of 
action of this enzyme involves hydrolysis of the amide bond between the first GlcNAc of the N-glycan and the side chain of Asx. This linkage is very well conserved in eukaryotic cells. However, in bacterial proteins, carbohydrate-peptide linkages are different and PNGase F is not capable of hydrolyzing this linkage. For example, the structure of the N-linked glycan present on multiple glycoproteins in the Gram-negative bacterium Campylobacter jejuni is GalNAc- $\alpha 1,4$-GalNAc- $\alpha 1,4$-[Glc- $\beta 1,3-]$ GalNAc- $\alpha 1,4-G a l N A c-$ $\alpha 1,4$-GalNAc- $\alpha 1,3$-Bac- $\beta 1, N$-Asn-Xaa, where Bac is bacillosamine, 2,4-diacetamido-2,4,6-trideoxyglucopyranose ${ }^{39}$. Recently, a new glycomics strategy, based on the combination of non-specific proteolytic digestion and permethylation, was devised that can be used for bacterial glycoproteins ${ }^{40}$. The glycomics approach that we propose is not applicable to bacterial proteins. However, the other methods described in this protocol, such as permethylation, linkage analysis, exoglycosidase digestion and MS, can obviously be used to determine the carbohydrate structure of bacterial glycoproteins. In addition, the sodium hydroxide method described in this protocol is the simplest approach to permethylation of glycans. However, this method cannot be used if the glycans are sulfated, in which case the Hakomori protocol must be used ${ }^{41}$.

The strategies in glycoprotein analysis depend on the amount of available sample. If less than $50 \mu \mathrm{g}$ of protein is available, permethylation derivatization on PNGase F-released glycans from glycoproteins can be performed and permethylated PNGase F-released glycans are analyzed by MALDI-TOF-MS, MS/MS sequencing and linkage analysis. Exoglycosidase digestions can be performed on the MALDI target. When glycoproteins are isolating from gel spots in electrophoresis, they are most often available at only picomolar quantities. For this reason, permethylation derivatization and obviously linkage analysis cannot be performed on PNGase F-released glycans from glycoproteins isolating from gel spots in electrophoresis unless these glycoproteins are abundant. Therefore, PNGase F-released glycans from glycoproteins isolated from gel spots in electrophoresis are analyzed by MALDI-TOF-MS without derivatization in the linear negative ion mode or in the reflectron positive ion mode after a chemical desialylation. Exoglycosidase digestions can also be performed on the MALDI target. All structural assignments are made on the basis of the MALDI mass and exoglycosidase digestions. The results of these experiments would normally be sufficient for identification.
TABLE 2 | Most commonly encountered B-type ions corresponding to non-reducing structures in sodiated permethylated glycans.

\begin{tabular}{ll}
\hline Mass & B-type ion \\
\hline 282 & $\mathrm{HexNAc}_{1}+\mathrm{Na}^{+}$ \\
398 & $\mathrm{NeuAc}_{1}+\mathrm{Na}^{+}$ \\
486 & $\mathrm{Hex}_{1} \mathrm{HexNAc}_{1}+\mathrm{Na}^{+}$ \\
527 & $\mathrm{HexNAc}_{2}+\mathrm{Na}^{+}$ \\
660 & $\mathrm{Fuc}_{1} \mathrm{Hex}_{1} \mathrm{HexNAc}_{1}+\mathrm{Na}^{+}$ \\
690 & $\mathrm{Hex}_{2} \mathrm{HexNAc}_{1}+\mathrm{Na}^{+}$ \\
701 & $\mathrm{Fuc}_{1} \mathrm{HexNAc}_{2}+\mathrm{Na}^{+}$ \\
731 & $\mathrm{HexNAc}_{1} \mathrm{Hex}_{1} \mathrm{HexNAc}_{1}+\mathrm{Na}^{+}$ \\
834 & $\mathrm{Fuc}_{2} \mathrm{Hex}_{1} \mathrm{HexNAc}_{1}+\mathrm{Na}^{+}$ \\
847 & $\mathrm{NeuAc}_{1} \mathrm{Hex}_{1} \mathrm{HexNAc}_{1}+\mathrm{Na}^{+}$ \\
935 & $\mathrm{Hex}_{2} \mathrm{HexNAc}_{2}+\mathrm{Na}^{+}$ \\
1,021 & $\mathrm{NeuAc}_{1} \mathrm{Fuc}_{1} \mathrm{Hex}_{1} \mathrm{HexNAc}_{1}+\mathrm{Na}^{+}$ \\
\hline
\end{tabular}

Determination of sialic acid residues that often occur in glycoprotein glycans is not possible using the linkage analysis described in this protocol. The presence and linkage positions of these sugar constituents must be indirectly established by methylation analysis before and after desialylation. To prove the presence of sialic acid residues, methylated oligosaccharides can also be degraded by methanolysis ${ }^{42}$. It is also important to know that, under the experimental conditions described, alkali-labile substituants are lost during methylation.

\section{Applications of this approach}

Recently, we have successfully applied this approach to the analysis of different glycoproteins, including galactommanoproteins of Aspergillus fumigatus ${ }^{6}$, excreted/secreted glycoproteins of the parasite Giardia intestinalis ${ }^{7}$, bovine lysosomal $\alpha$-mannosidase $^{5}$ and recombinant human thyrotropin ${ }^{8}$. We have also identified acquired modifications of glycosylation by applying this approach to the serum of patients with cirrhosis ${ }^{9}$. In addition, more recently, this approach has been used to propose a rapid mass spectrometric strategy for the characterization of $\mathrm{N}$ - and $\mathrm{O}$-glycan chains in the diagnosis of congenital disorders of glycosylation ${ }^{10}$. Thus, this approach can be used to study the glycosylation of isolated complex glycoproteins or of numerous glycoproteins encountered in a complex biological medium (e.g., fluid, cells, organ, tissue).

TABLE 3 | Exoglycosidases and conditions used to confirm structure assignments made from matrix-assisted laser desorption/ionization-time of flight mass spectrometry experiments.

\begin{tabular}{llll}
\hline Enzyme & Source & Specificity & Buffer
\end{tabular}

Exoglycosidase digestions are carried out on released glycans at $37^{\circ} \mathrm{C}$ for $48 \mathrm{~h}$. After $24 \mathrm{~h}$, a second aliquot of enzyme is added. The amount of enzyme indicated in the table corresponds only to the first aliquot of enzyme. After each exoglycosidase digestion, a small aliquot is permethylated and analyzed by matrix-assisted laser desorption/ionization-time of flight mass spectrometry and linkage analysis. 


\section{MATERIALS}

\section{REAGENTS}

-2,4,6-trihydroxyacetophenone (THAP; Sigma)

-2.5-Dihydroxybenzoic acid (DHB; Sigma)

- Acetic acid (Fluka)

- Acetic anhydride (Sigma)

- Acetonitrile (MeCN; Acros Organics) ! CAUTION MeCN should be handled in a hood using gloves.

- Ammonium hydroxide ( $\mathrm{NH}_{4} \mathrm{OH}$; Acros Organics)

- Ammonium acetate (Sigma)

- Ammonium hydrogen carbonate (Sigma)

- Ammonium formate (Sigma)

- Arthrobacter ureafaciens sialidase (Roche)

- Bovine kidney $\alpha$-fucosidase (Sigma)

- Bovine testes $\beta$-galactosidase (Sigma)

- Coomassie blue dye (Biorad)

- Chlorhydrate guanidinium

- Cyanogen bromide

- Carboxamidomethylated glycoprotein

- Chloroform

- Jack bean $\alpha$-mannosidase (Sigma)

- Jack bean $\beta-N$-acetylhexosaminidase (Sigma)

- $\beta$-mercaptoethanol (Biorad)

- Diammonium citrate (DAC; Sigma)

-DMSO (Fluka)

-DTT (Biorad)

- Dowex beads $(50 \times 8,50-100$ mesh; Biorad $)$

-Ethanol (Carlo Erba Reactifs-SDS)

- Methanol (Carlo Erba Reactifs-SDS) ! CAUTION Methanol should be

handled in a hood using gloves.

- Hydrochloric acid (HCl; Fluka)

- Iodoacetamide (IAA; Biorad)

- Iodomethane $\left(\mathrm{ICH}_{3}\right.$; Fluka) ! CAUTION $\mathrm{ICH}_{3}$ is highly toxic and should be handled in a hood using gloves.

- NP40 (BDH Chemicals, Poole, UK) (see REAGENT SETUP)

- Potassium ferricyanide (Sigma)

- Pyridine (Fluka) ! CAUTION Pyridine should be handled in a hood using gloves.

$\cdot \mathrm{NaBH}_{4}$ (Sigma)

- Sodium borodeuteride $\left(\mathrm{NaBD}_{4}\right.$; Sigma $)$

- SDS (Biorad)

- Sodium hydroxide (NaOH; Carlo Erba Reactifs-SDS)

- Sodium thiosulfate (Sigma)

- Trifluoroacetic acid (TFA; Fluka) ! CAUTION TFA should be handled in a hood using protective eyewear and gloves.

- Trypsin (Sigma)

- Dowex resin $\Delta$ CRITICAL It is essential to use the highest-quality solvents for every purpose.

EQUIPMENT

- Column of $150 \mathrm{mg}$ of non-porous graphitized carbon (Alltech)
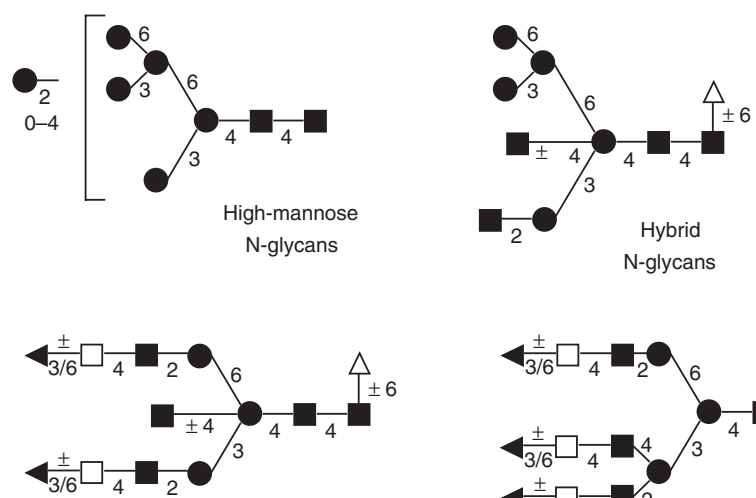

Biantennary

complex N-glycans

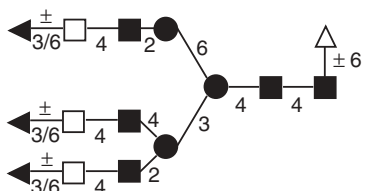

Triantennary complex $\mathrm{N}$-glycans

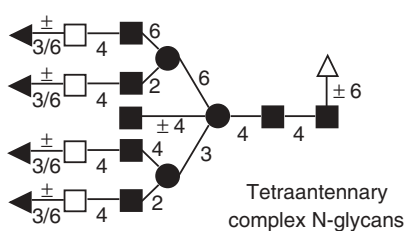

Figure 6 | The different classes of $\mathrm{N}$-linked glycans. Symbols: open square, galactose; closed square, $\mathrm{N}$-acetylglucosamine; open triangle, fucose; closed triangle, $\mathrm{N}$-acetyl-neuraminic acid; closed circle, mannose.

- Sep-Pak $\mathrm{C}_{18}$ cartridge (Waters)

-Spectra/Por regenerated cellulose membrane no. 1 (cut off 6-8 kDa) (VWR)

- SpeedVac concentrator (Eppendorf)

- MALDI-TOF-MS (Voyager Elite DE-STR Pro; PerSeptive Biosystem, Applied Biosystems, Framingham, MA) equipped with a pulsed nitrogen laser $(337 \mathrm{~nm})$ and a gridless delayed extraction ion source

-Q-TOF MS (Q-STAR Pulsar; Applied Biosystems/MDS Sciex, Toronto, Canada) fitted with a nano-electrospray ion source (Protana, Odense, Denmark)

- Goldcoated 'medium-length' borosilicate capillaries (Protana, Toronto,

Ontario, Canada)

- GC-MS instrument (Carbo Erba GC 8000 gas chromatograph (Carbo Erba) coupled to a Finnigan Automass II mass spectrometer, Finnigan)

- CP-Sil5 CB low-bleed capillary column, $25 \mathrm{~m} \times 0.32 \mathrm{~mm}, 0.25-\mu \mathrm{m}$ film phase (Chrompack, France)

REAGENT SETUP

Glycoprotein sample This protocol enables the analysis of 5-20 $\mu \mathrm{g}$ of glycoprotein directly from SDS-PAGE or 2D-gels (N-glycans) or from $20 \mu \mathrm{g}$ to

TABLE 4 | GC-MS analysis of partially methylated alditol acetates obtained from PNGase F-released N-glycans from human serum.

\begin{tabular}{lllc}
\hline Retention time $(\mathbf{m i n})$ & Characteristic fragment ions $(\mathbf{m} / \mathbf{z})$ & Assignment & Relative abundance \\
\hline 15.29 & $115,118,131,162,175$ & Terminal Fuc & 0.06 \\
19.55 & $102,118,129,145,161,162,205$ & Terminal Man & 0.02 \\
20.46 & $102,118,129,145,161,162,205$ & Terminal Gal & 0.06 \\
23.55 & $129,130,161,190$ & 2 -linked Man & 0.54 \\
24.46 & $118,129,161,234$ & 3 -linked Gal & 0.04 \\
26.42 & $99,102,118,129,162,189,233$ & 6 -linked Gal & 0.42 \\
28.02 & $130,190,233$ & 2,4 -linked Man & 0.03 \\
29.29 & $129,130,189,190$ & 2,6 -linked Man & 0.03 \\
29.51 & $118,129,189,234$ & 3,6 -linked Man & 0.21 \\
31.10 & 118,333 & $3,4,6$-linked Man & 0.01 \\
32.16 & $117,159,203,205$ & Terminal GlcNAc & 0.05 \\
34.33 & $117,159,233$ & $4-$-linked GlcNAc & 1.00 \\
35.23 & 118,233 & $4-$ linked HexNAc & 0.02 \\
36.46 & 118,129 & 3,4 -linked GlcNAc & 0.01 \\
37.58 & $117,159,261$ & 4,6 -linked GlcNAc & 0.08 \\
\hline
\end{tabular}


$2 \mathrm{mg}$ of glycoprotein following PNGase F digestion for N-glycans and reductive elimination for O-glycans. The gel pieces can be Coomassie blue-stained or silver-stained. If the sample is not analyzed directly from SDS-PAGE or 2D-gels, it can be freeze-dried or in solution. It is important to desalt the glycoprotein if the concentration of salts is high.

In-solution denaturing buffer $50 \mathrm{mM}$ ammonium bicarbonate ( $\mathrm{pH} 8.3$ ), $1 \%$ SDS and $1 \% \beta$-mercaptoethanol.

NP40 10\% (vol/vol) NP40 is diluted in $50 \mathrm{mM}$ ammonium bicarbonate. Recombinant PNGase F (Roche) Lyophilized PNGase F is dissolved in pure

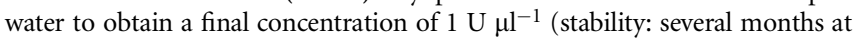
$4{ }^{\circ} \mathrm{C}$ ). $\Delta$ CRITICAL Some commercial PNGase F can be stored at $-20{ }^{\circ} \mathrm{C}$ in presence of glycerol. However, for the MALDI-TOF-MS studies, glycerol prevents the co-crystallization of the DHB matrix and the sample. For this reason, we only use a freeze-dried PNGase F without glycerol. In addition, PNGase F releases practically all N-glycans except those with fucose attached to the 3-position of the Asn-linked GlcNAc residue. Their corresponding glycoproteins are commonly found in plants and in insect cells. Such PNGase F-resistant glycans have been found to be sensitive to PNGase $\mathrm{A}^{12}$.

Reduction/alkylation buffer $0.6 \mathrm{M}$ Tris- $\mathrm{HCl}$ solution containing $6 \mathrm{M}$ chlorhydrate guanidinium, $\mathrm{pH}$ 8.4. Bubble with nitrogen for $30 \mathrm{~min}$ before use. Reduction buffer $1500 \mathrm{mM}$ DDT solution in the reduction/alkylation buffer. Alkylating buffer $13 \mathrm{M}$ IAA solution in the reduction/alkylation buffer. $\triangle$ CRITICAL This solution must be kept in the dark.

Reduction buffer $210 \mathrm{mM}$ DTT solution containing $100 \mathrm{mM}$ ammonium hydrogen carbonate.

Alkylating buffer $255 \mathrm{mM}$ IAA solution containing $100 \mathrm{mM}$ ammonium hydrogen carbonate.

Reductive elimination solution $50 \mathrm{mM} \mathrm{NaOH}, 1 \mathrm{M} \mathrm{NaBH}_{4}$.

DHB matrix solution Methanol/1 $\mathrm{mM}$ sodium acetate $(1: 1, \mathrm{vol} / \mathrm{vol})$

containing $10 \mathrm{mg}$ of DHB per $\mathrm{ml}$.

THAP matrix solution MeCN/DAC $20 \mathrm{mM}(1: 1, \mathrm{vol} / \mathrm{vol})$ containing $20 \mathrm{mg}$ of THAP monohydrate per ml.

TFA solution $0.1 \%$ TFA in water ( $\mathrm{vol} / \mathrm{vol})$.

Ethanol solution Ethanol/water (1:1, vol/vol).

Reduction solution $2 \mathrm{M} \mathrm{NH}_{4} \mathrm{OH}$ containing $4 \mathrm{mg}$ of $\mathrm{NaBD}_{4}$ per $\mathrm{ml}$. EQUIPMENT SETUP

Desalting column The desalting column is a Pasteur pipette plugged at the tapered end with a small amount of glass wool. A piece of silicone tubing (approximately $2 \mathrm{~cm}$ ) is placed at the tapered end, and the flow is blocked using an adjustable clip. Fill the pipette with $5 \%(\mathrm{vol} / \mathrm{vol})$ acetic acid and open the clip slightly to let the equilibration buffer slowly flow out. While the acetic acid is running out, the column is filled with $2 \mathrm{ml}$ of freshly washed Dowex beads $(50 \times$ $8, \mathrm{H}^{+}$form). The use of Pasteur pipettes limits the volume of Dowex resin to $2 \mathrm{ml}$. In these conditions, it is possible to remove cationic materials (sodium salts, amino acids and peptides) obtained from the reductive treatment of glycoproteins fully up to $2 \mathrm{mg}$.

Linkage analysis of PMAAs by GC-MS The temperature of the Ross injector is $260^{\circ} \mathrm{C}$. Samples are analyzed using a temperature program starting with a
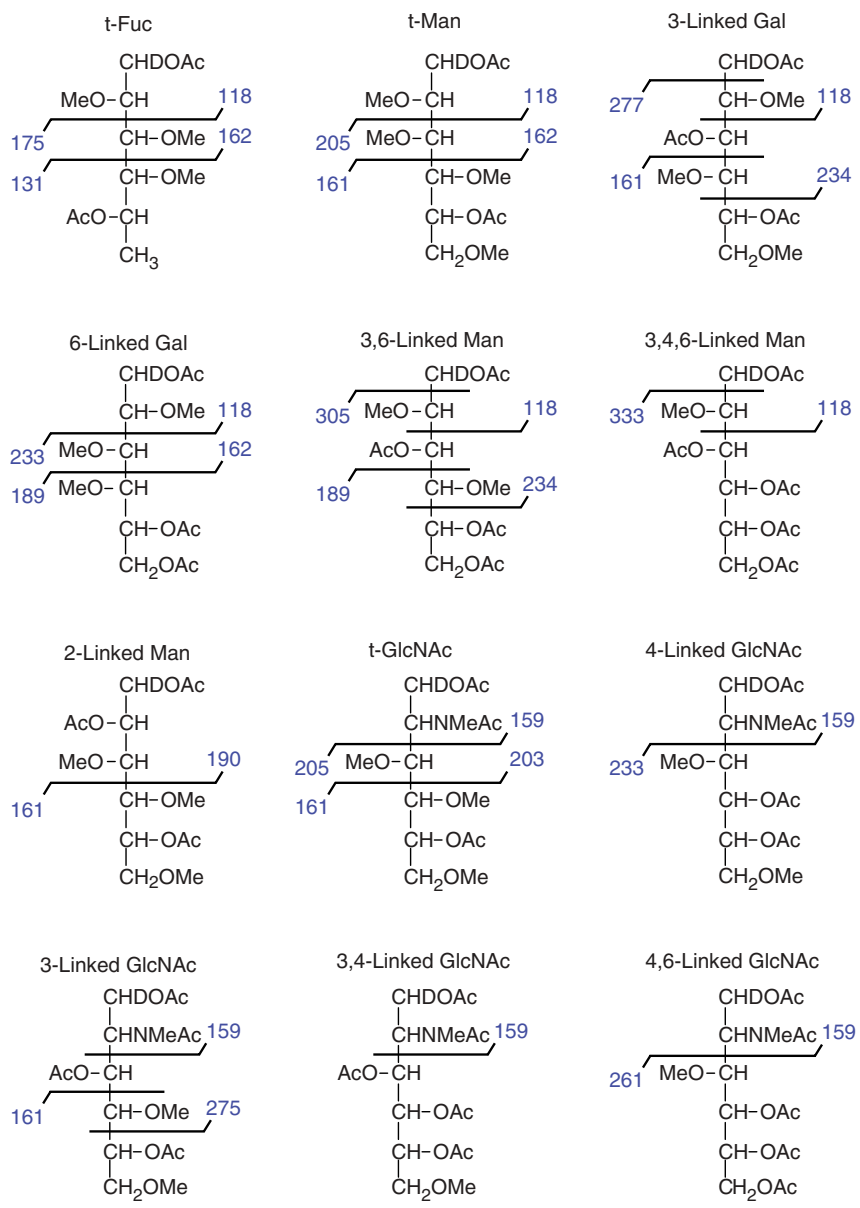

Figure 7 | Primary fragments obtained in electron impact (EI) mass spectrometry of the most common partially methylated alditol acetates (PMAAs) obtained from $\mathrm{N}-$ glycans.

gradient of $2{ }^{\circ} \mathrm{C} \min ^{-1}$ from 130 to $180{ }^{\circ} \mathrm{C}$, after 2 min at $130{ }^{\circ} \mathrm{C}$, followed by a gradient of $4{ }^{\circ} \mathrm{C} \mathrm{min}-1$ until $240{ }^{\circ} \mathrm{C}$. The column is coupled to a Finnigan Automass II mass spectrometer. Analyses are performed in the EI mode using an ionization energy of $70 \mathrm{eV}$. Quantification of the various PMAA derivatives is carried out using total ion current of the MS detector in positive ion mode.

\section{PROCEDURE}

\section{$\mathrm{N}$-glycan release}

1| Prepare N-glycan samples (Fig. 1) in one of the following ways: in-solution deglycosylation after denaturation of glycoproteins with SDS (option A), in-solution deglycosylation after reduction and alkylation of glycoproteins (option B) or in-gel deglycosylation (option C). Choose option A if less than $50 \mu \mathrm{g}$ of protein is available. If more than $50 \mu \mathrm{g}$ of protein is available, we use option B. If large amounts of protein (more than $1 \mathrm{mg}$ ) are used or if glycoproteins of interest could be contaminated by oligosaccharides or anything else (typically glycoproteins extracted from any fluid, cells, organ, tissue etc.), we prefer to use option B. After reduction, alkylation and digestion with a protease, the resulting peptides/glycopeptides can be purified using Sep-Pak $\mathrm{C}_{18}$ before PNGase $\mathrm{F}$ digestion. This optional step removes possible contaminants. The protocol to condition the Sep-Pak $\mathrm{C}_{18}$ column and to purify the sample is described in Step 2B. In this case, only the fraction that corresponds to a mixture of peptides and glycopeptides is collected and freeze-dried after removing MeCN under a stream of nitrogen in a hood. Before in-gel deglycosylation (option C), protein bands are excised from the gel and destained. Glycoproteins need to be reduced and carbamidomethylated in the gel to ensure complete PNGase F deglycosylation.

\section{(A) In-solution deglycosylation after denaturation of glycoproteins with SDS}

(i) Dissolve the glycoprotein sample in $200 \mu \mathrm{l}$ of in-solution denaturing buffer (see REAGENT SETUP).

(ii) Incubate in a boiling water bath for 20 min.

(iii) Leave the mixture at room temperature $\left(20^{\circ} \mathrm{C}\right)$ for $20 \mathrm{~min}$. 
(iv) Add $200 \mu \mathrm{l}$ of $50 \mathrm{mM}$ ammonium hydrogen carbonate and $20 \mu \mathrm{l}$ of 10\% NP40 (vol/vol) (see REAGENT SETUP).

(v) Leave the mixture at room temperature for 5 min.

(vi) Add $3 \mu$ l of the PNGase F enzyme solution (see REAGENT SETUP).

(vii) Incubate at $37^{\circ} \mathrm{C}$ overnight.

(viii) Evaporate the mixture to dryness in a SpeedVac concentrator at room temperature for approximately $3 \mathrm{~h}$. At this point, if you are not interested in studying the 0-glycans of the proteins, you can proceed directly to the purification of the $\mathrm{N}$-glycans using a non-porous graphitized carbon column (Step 2A). Otherwise, it is necessary to separate the proteins from PNGase F-released $\mathrm{N}$-glycans by precipitating the $\mathrm{N}$-deglycosylated proteins.

PAUSE POINT The mixture is stable for at least several months when stored at $-20{ }^{\circ} \mathrm{C}$.

(ix) Re-dissolve the sample in $200 \mu \mathrm{l}$ of $50 \mathrm{mM}$ ammonium hydrogen carbonate and precipitate the $\mathrm{N}$-deglycosylated proteins using three volumes of ethanol and incubating for $2 \mathrm{~h}$ at $-20^{\circ} \mathrm{C}$.

(x) Centrifuge the mixture at $8,000 \mathrm{~g}$ for $10 \mathrm{~min}$ at $4^{\circ} \mathrm{C}$ and transfer the $\mathrm{N}$-glycan-containing supernatant into a 4-ml vial.

(xi) Repeat Steps $1 \mathrm{~A}(\mathrm{ix})$ and $1 \mathrm{~A}(\mathrm{x})$ twice. The pooled $\mathrm{N}$-glycan-containing supernatants are evaporated under a stream of nitrogen and then freeze-dried. The washed pellets containing the $\mathrm{N}$-deglycosylated protein are also freeze-dried.

The $\mathrm{N}$-glycans are purified using a Sep-Pak $\mathrm{C}_{18}$ to remove SDS (see Step 2B). The washed pellets are subjected to reductive elimination to release 0 -glycans (see Step 3).

PAUSE POINT The $\mathrm{N}$-glycans and the washed pellets containing the $\mathrm{N}$-deglycosylated proteins are stable for at least several months when stored at $-20^{\circ} \mathrm{C}$.

(B) In-solution deglycosylation after reduction and alkylation of glycoproteins

(i) Dissolve the glycoprotein sample in $200 \mu \mathrm{l}$ of reduction/alkylation buffer (see REAGENT SETUP). The volume may be increased to ensure solubility.

(ii) Incubate at $45^{\circ} \mathrm{C}$ for $90 \mathrm{~min}$.

(iii) Prepare reduction buffer 1 just before use.

(iv) Add the appropriate amount of freshly prepared reduction buffer 1 to the glycoprotein solution to obtain a final concentration of $20 \mathrm{mM}$ DTT. Flush the mixture with argon (or nitrogen) and incubate at $45^{\circ} \mathrm{C}$ for $4 \mathrm{~h}$.

(v) Prepare alkylating buffer 1 just before use and keep it in the dark.

(vi) Add the appropriate amount of freshly prepared alkylating buffer 1 to the glycoprotein solution to obtain a final concentration of $110 \mathrm{mM}$ IAA. Flush the mixture with argon (or nitrogen) and leave in the dark at room temperature overnight.

(vii) Desalt the carboxamidomethylated glycoprotein by dialyzing against $4 \times 2 \mathrm{l}$ of $50 \mathrm{mM}$ ammonium hydrogen carbonate at $4{ }^{\circ} \mathrm{C}$, with each change occurring after stirring for $12 \mathrm{~h}$.

(viii) Freeze-dry the carboxamidomethylated glycoprotein.

- PAUSE POINT The sample is stable for at least several months when stored at $-20{ }^{\circ} \mathrm{C}$.

(ix) Dissolve the carboxamidomethylated glycoprotein sample in $200 \mu \mathrm{l}$ of freshly prepared $50 \mathrm{mM}$ ammonium hydrogen carbonate solution. The volume may be increased to ensure solubility.

(x) Weigh out the appropriate amount of trypsin and dissolve in the $50 \mathrm{mM}$ ammonium hydrogen carbonate solution to a concentration of $5 \mu \mathrm{g} \mu \mathrm{l}^{-1}$.

$\triangle$ CRITICAL STEP Prepare the trypsin solution just before use. Since PNGase F enzyme does not release any N-glycans when glycosylation sites are on the first or last amino acid residue of a peptide, the protease must be carefully chosen ${ }^{8}$. For this reason, when PNGase F digestion is performed on a glycoprotein, the amino acid sequence of this glycoprotein must be known. Trypsin can be replaced by other proteases or by a chemical reagent such as cyanogen bromide to generate glycopeptides such that glycosylation sites are not present on the first amino acid residue.

(xi) Add the trypsin solution to the carboxamidomethylated glycoprotein solution to obtain an enzyme-to-substrate ratio of $1: 20(w t / w t)$.

(xii) Incubate at $37{ }^{\circ} \mathrm{C}$ for $24 \mathrm{~h}$ under gentle agitation.

(xiii) After heating the solution at $100{ }^{\circ} \mathrm{C}$ for $10 \mathrm{~min}$, freeze-dry the sample.

$\triangle$ CRITICAL STEP It is important to destroy trypsin before releasing N-glycans using PNGase F.

- PAUSE POINT The sample is stable for at least several months when stored at $-20{ }^{\circ} \mathrm{C}$.

(xiv) Dissolve the resulting peptide/glycopeptide mixture in $200 \mu \mathrm{l}$ of freshly prepared $50 \mathrm{mM}$ ammonium hydrogen carbonate solution. The volume may be increased to ensure solubility.

(xv) Add $3 \mu \mathrm{l}$ of the PNGase F enzyme solution (see REAGENT SETUP).

(xvi) Incubate at $37^{\circ} \mathrm{C}$ overnight.

(xvii) Freeze-dry the sample.

PAUSE POINT The mixture is stable for at least several months when stored at $-20{ }^{\circ} \mathrm{C}$.

(C) In-gel deglycosylation and extraction of $\mathrm{N}$-glycans

(i) Destain the silver-stained gel pieces with a solution containing $30 \mathrm{mM}$ potassium ferricyanide solution and $100 \mathrm{mM}$ sodium thiosulfate with shaking. 
(ii) Destain the Coomassie blue-stained gel pieces with a solution of $100 \mathrm{mM}$ ammonium hydrogen carbonate in $50 \% \mathrm{MeCN}$ $(1: 1, \mathrm{vol} / \mathrm{vol})$ with shaking.

$\triangle$ CRITICAL STEP SDS has to be thoroughly removed from the gel to prevent denaturation of the PNGase F enzyme ${ }^{14}$.

PAUSE POINT Gel pieces can also be left overnight at $4{ }^{\circ} \mathrm{C}$ in this solution without shaking. This helps to remove the Coomassie stain.

(iii) Wash the gel pieces three times with pure water for 10 min with shaking.

(iv) Dehydrate the gel pieces three times with MeCN for 5 min with shaking.

(v) Dry the gel pieces at room temperature for approximately 30 min in a SpeedVac concentrator.

PAUSE POINT The dried gel pieces can be left overnight at $4{ }^{\circ} \mathrm{C}$ if you cannot proceed immediately.

(vi) Cover the dried gel pieces with reduction buffer 2 and incubate at $56^{\circ} \mathrm{C}$ for $30 \mathrm{~min}$.

$\triangle$ CRITICAL STEP Prepare reduction buffer 2 just before use.

(vii) Remove reduction buffer 2, cover the gel pieces with alkylating buffer 2 and incubate in the dark at room temperature for $30 \mathrm{~min}$.

$\triangle$ CRITICAL STEP Prepare alkylating buffer 2 just before use and keep it in the dark.

(viii) Remove the alkylating buffer and wash the gel pieces three times with pure water for 10 min with shaking.

(ix) Dehydrate the gel pieces three times with MeCN for 5 min with shaking.

(x) Dry the gel pieces at room temperature for approximately $30 \mathrm{~min}$ in a SpeedVac concentrator.

PAUSE POINT The dried gel pieces can be left overnight at $4{ }^{\circ} \mathrm{C}$ if you cannot proceed immediately.

(xi) Add $3 \mu \mathrm{l}$ of the PNGase F enzyme solution to the dried gel pieces (see REAGENT SETUP) and leave the gel pieces at room temperature for $5 \mathrm{~min}$.

(xii) Cover the gel pieces with $50 \mathrm{mM}$ ammonium hydrogen carbonate buffer and incubate at $37^{\circ} \mathrm{C}$ overnight.

(xiii) Extract glycans from the gel pieces by removing the incubation buffer followed by three extractions with approximately $300 \mu \mathrm{l}$ of pure water and two extractions with $50 \% \mathrm{MeCN}$, with sonication for 30 min each. All extracts and the removed incubation buffer are combined and dried in a SpeedVac concentrator at room temperature.

PAUSE POINT The glycans are stable for at least several months when stored at $-20{ }^{\circ} \mathrm{C}$.

\section{$\mathrm{N}$-glycan purification}

2| Purify PNGase F-released $\mathrm{N}$-glycans by either $\mathrm{N}$-glycan purification using a non-porous graphitized carbon column (option A), N-glycan purification using a Sep-Pak $\mathrm{C}_{18}$ cartridge (option $\mathrm{B}$ ) or $\mathrm{N}$-glycan purification using a non-porous graphitized carbon mini-column (option C). Choose option A if you release $\mathrm{N}$-glycans after denaturation of glycoproteins with SDS and if you are not interested in studying the 0-glycosylation of proteins. Choose option B in two cases: (i) if you release $\mathrm{N}$-glycans after denaturation of glycoproteins with SDS and if you are interested in studying the 0-glycosylation of proteins (in this case, the Sep-Pak $\mathrm{C}_{18}$ cartridge will remove SDS from N-glycans); (ii) if you release $\mathrm{N}$-glycans after reduction/ alkylation and proteolytic digestion of glycoproteins (in this case, the Sep-Pak $\mathrm{C}_{18}$ cartridge will separate PNGase F-released $\mathrm{N}$-glycans from the mixture of peptides and 0-glycopeptides). Choose option C if you release $\mathrm{N}$-glycans from gel-separating proteins. When glycoproteins are isolating from gel spots in electrophoresis, optimization of methods for purification and analysis of glycans is required. In this case, glycoproteins are most often available at only picomolar quantities. For this reason, though the non-porous graphitized carbon mini-column may be used to purify sialylated glycans, we first desialylate PNGase F-released N-glycans. The chemical desialylation results in maximum sensitivity for the MALDI-TOF-MS analysis of $\mathrm{N}$-glycans without using permethylation derivatization in the positive reflectron ion mode.

\section{(A) N-glycan purification using a non-porous graphitized carbon column}

(i) After PNGase F digestion in the presence of SDS and evaporating the mixture to dryness, re-dissolve the sample in $500 \mu \mathrm{l}$ to $1 \mathrm{ml}$ of $0.1 \%$ TFA solution ( $\mathrm{vol} / \mathrm{vol}$ ) for loading on to a column of non-porous graphitized carbon ${ }^{43}$.

(ii) Condition the column of $150 \mathrm{mg}$ of non-porous graphitized carbon with $5 \mathrm{ml}$ of methanol and wash it with $10 \mathrm{ml}$ of $0.1 \%$ TFA.

(iii) Load the sample on to the column and remove salts with $15 \mathrm{ml}$ of $0.1 \%$ TFA.

(iv) Recover N-glycans by passing through the column $3 \mathrm{ml}$ of $25 \% \mathrm{MeCN}$ in $0.1 \%$ TFA and directly freeze-dry. This protocol efficiently removes salts, SDS and $\mathrm{N}$-deglycosylated proteins. However, 0 -glycans cannot be released from N-deglycosylated proteins using this protocol.

$\triangle$ CRITICAL STEP Do not use a more hydrophobic solution to elute N-glycans; if you do, SDS could also be eluted with N-glycans.

PAUSE POINT The glycans are stable for at least several months when stored at $-20{ }^{\circ} \mathrm{C}$.

(B) $\mathrm{N}$-glycan purification using a Sep-Pak $\mathrm{C}_{18}$ column

(i) Dissolve the sample in $100-200 \mu$ of $5 \%$ acetic acid.

(ii) Condition the Sep-Pak $\mathrm{C}_{18}$ column with $5 \mathrm{ml}$ of methanol and then with $10 \mathrm{ml}$ of $5 \%$ acetic acid. 
(iii) Load the sample on to the column and elute stepwise with $3 \mathrm{ml}$ of $5 \%$ acetic acid and $4 \mathrm{ml}$ of $5 \%$ acetic acid in $80 \% \mathrm{MeCN}$.

(iv) Collect each fraction. The N-glycans are eluted with 5\% acetic acid. The fraction eluted with $5 \%$ acetic acid in $80 \% \mathrm{MeCN}$ is collected only when PNGase F digestion has been performed after reduction/alkylation and proteolytic digestion of glycoproteins. This fraction that corresponds to a mixture of peptides and 0-glycopeptides will be subjected to reductive elimination (see Step 3).

(v) Remove MeCN under a stream of nitrogen in a hood.

(vi) Freeze-dry each fraction.

PAUSE POINT Samples are stable for at least several months when stored at $-20{ }^{\circ} \mathrm{C}$.

(C) N-glycan purification using a non-porous graphitized carbon mini-column

(i) Dissolve the sample in $200 \mu \mathrm{l}$ of $2 \mathrm{M}$ acetic acid.

(ii) Incubate at $80^{\circ} \mathrm{C}$ for $2 \mathrm{~h}$.

(iii) Evaporate the sample to dryness at room temperature for approximately $1 \mathrm{~h}$ in a SpeedVac concentrator.

PAUSE POINT The glycans are stable for at least several months when stored at $-20{ }^{\circ} \mathrm{C}$.

(iv) Prepare mini-columns by dismantling a column of $150 \mathrm{mg}$ of non-porous graphitized carbon (Alltech).

(v) Pack $200-\mu$ l filter pipette tips with approximately $5 \mathrm{mg}$ of non-porous graphitized carbon.

(vi) Condition the mini-column by sequential washing with $1 \mathrm{ml}$ of methanol and $2 \mathrm{~mL}$ of $0.1 \%$ TFA.

(vii) Dissolve the extracted glycans in $0.1 \%$ TFA and load the sample on to the column.

(viii) Purify the sample with $2 \mathrm{ml}$ of $0.1 \%$ TFA.

(ix) Recover $\mathrm{N}$-glycans by passing through the mini-column $500 \mu \mathrm{l}$ of $25 \% \mathrm{MeCN}$ in $0.1 \%$ TFA.

(x) Evaporate the sample to dryness at room temperature for approximately $2 \mathrm{~h}$ in a SpeedVac concentrator.

PAUSE POINT Glycans are stable when stored at $-20^{\circ} \mathrm{C}$.

\section{0-glycan release}

3| Dissolve the $\mathrm{N}$-deglycosylated proteins (Step 2A) or the resulting peptides/glycopeptides (Step 2B) in $200 \mu$ l of reductive elimination solution (see REAGENT SETUP).

$\triangle$ CRITICAL STEP Prepare the reductive elimination solution just before use.

4| Incubate at $45{ }^{\circ} \mathrm{C}$ overnight.

5| Stop the reaction by adding acetic acid dropwise until no fizzing is observed (approximately three drops).

\section{0-glycan purification}

6| Pre-treat Dowex beads (50 $\times 8, \mathrm{H}^{+}$form, 50-100 mesh). Wash twice with $3 \mathrm{M} \mathrm{NaOH}$ for 30 min at room temperature.

7| Wash extensively with water until the $\mathrm{pH}$ of the water wash measured by paper $\mathrm{pH}$ is slightly below 7 .

8| Wash twice with $3 \mathrm{M} \mathrm{HCl}$ for $30 \mathrm{~min}$ at room temperature.

9| Wash extensively with water until the $\mathrm{pH}$ of the water wash is slightly below 7 .

10| Wash three times with $5 \%$ acetic acid.

PAUSE POINT Beads can be stored in the $5 \%$ acetic acid solution for several months at room temperature.

11 Pack a Pasteur pipette, plugged at the tapered end with a small amount of glass wool, with the Dowex beads (see REAGENTS). The use of Pasteur pipettes limits the volume of Dowex resin to $2 \mathrm{ml}$. In these conditions, it is possible to remove cationic materials (sodium salts, aminoacids and peptides) obtained from the reductive treatment of glycoproteins fully up to $2 \mathrm{mg}$.

12| Wash the column with 5 volumes of $5 \%$ acetic acid (approximately $10 \mathrm{ml}$ ).

13| Load the sample on to the column and elute with $4 \mathrm{ml}$ of $5 \%$ acetic acid.

14| Collect two fractions of $2 \mathrm{ml}$.

15| Freeze-dry immediately.

- PAUSE POINT Dried glycans are stable for at least several months when stored at $-20{ }^{\circ} \mathrm{C}$.

16| Remove borate salts by repeated evaporation with methanol containing $5 \%$ acetic acid $(5 \times 500 \mu \mathrm{l})$ under a stream of nitrogen in a hood. 
PROTOCOL

17| Add the second fraction to the first fraction and freeze-dry.

PAUSE POINT Dried glycans are stable for at least several months when stored at $-20{ }^{\circ} \mathrm{C}$.

\section{Exoglycosidase digestions}

18| If PNGase F-released glycans are isolated from gel-separated proteins, carry out exoglycosidase digestions on the MALDI target (option A); otherwise exoglycosidase digestions can be carried out in solution (option B).

\section{(A) Exoglycosidase digestions on the MALDI target}

(i) Mix $1 \mu \mathrm{l}$ of glycans (20 pmol) directly on-plate with $1 \mu \mathrm{l}$ of $20 \mathrm{mM}$ ammonium formiate, $\mathrm{pH}$ 4.6.

(ii) Add $1 \mu \mathrm{l}$ of each exoglycosidase on to each spotted sample at the following concentration: $\alpha$-sialidase, $50 \mathrm{mU}$; $\alpha$-galactosidase, $1.25 \mathrm{mU} ; \alpha-N$-acetylhexosaminidase, $150 \mathrm{mU} ; \alpha$-fucosidase, $7.7 \mathrm{mU}$. For each sample, the number of spots depends on the number of exoglycosidases, alone or in combination, to test.

(iii) Place the MALDI plate at $37{ }^{\circ} \mathrm{C}$ for $6 \mathrm{~h}$ in a crystallization beaker containing water to saturate atmosphere.

$\triangle$ CRITICAL STEP High-purity water must be regularly added to the spots to prevent air-drying.

(iv) Stop the enzymatic reactions by allowing the samples to dry at room temperature.

(v) Add $2 \mu \mathrm{l}$ of the DHB matrix solution and allow to dry at room temperature. The MALDI-TOF-MS analysis is performed as described below (Step 37).

(B) Exoglycosidase digestions in solution

(i) Dissolve glycans (typically $50 \%$ of PNGase F-released glycans) in $200 \mu \mathrm{l}$ of appropriate buffer (see Table 3).

(ii) Add the appropriate amount of exoglycosidase (see Table 3).

(iii) Incubate at $37^{\circ} \mathrm{C}$ for $48 \mathrm{~h}$. After $24 \mathrm{~h}$, a second aliquot of enzyme is added.

(iv) Stop the reaction by heating the solution at $100^{\circ} \mathrm{C}$ for 10 min.

(v) Take a small aliquot for permethylation (Step 19). The rest of sample is subjected to another exoglycosidase digestion.

(vi) Freeze-dry both aliquots.

$\triangle$ CRITICAL STEP Glycans must be freeze-dried just before permethylation in order to avoid under-methylation.

\section{Permethylation}

19| Place the glass tube containing the freeze-dried glycans in a vacuum vessel saturated with an argon atmosphere.

20| Add $500 \mu$ l of DMSO.

21| Place five to ten pellets of $\mathrm{NaOH}$ in a dry mortar.

Note: Transform the pellets of $\mathrm{NaOH}$ into a fine powder using the pestle rapidly.

22| Add approximately $25 \mathrm{mg}$ of $\mathrm{NaOH}$ to the sample.

23| Add $300 \mu \mathrm{l}$ of $\mathrm{ICH}_{3}$ and flush the tube with a stream of argon.

$\triangle$ CRITICAL STEP DMSO, $\mathrm{NaOH}$ and $\mathrm{ICH}_{3}$ must be kept under argon atmosphere. A glass tube must be used for the permethylation.

24| Mix vigorously and place the reaction mixture in an ultrasonic bath for $90 \mathrm{~min}$ at room temperature.

$\triangle$ CRITICAL STEP Do not leave the reaction mixture in the ultrasonic bath for more than 90 min to avoid artifacts.

25 Quench the reaction by addition of approximately $1 \mathrm{~mL}$ of $5 \%$ acetic acid at $4{ }^{\circ} \mathrm{C}$. Mix vigorously.

26| Add $600 \mu \mathrm{l}$ of chloroform. Mix vigorously, and allow the mixture to settle into two layers at $4{ }^{\circ} \mathrm{C}$.

27| Transfer the lower chloroform phase into a new glass tube.

28| Repeat Steps 26 and 27 twice.

29| Wash the chloroform phase eight times with 1 volume of water at $4{ }^{\circ} \mathrm{C}$ and discard aqueous phases.

30| Dry down the chloroform phase under a stream of nitrogen in a hood.

PAUSE POINT Permethylated glycans are stable for at least several months when stored at $-20{ }^{\circ} \mathrm{C}$.

\section{Purification of permethylated glycans}

31| Dissolve the sample in $100-200 \mu \mathrm{l}$ of methanol.

32| Condition the Sep-Pak $C_{18}$ column with $5 \mathrm{ml}$ of methanol and then with $10 \mathrm{ml}$ of water.

33| Load the sample on to the column and elute sequentially with $15 \mathrm{ml}$ of water, $2 \mathrm{ml}$ of $10 \% \mathrm{MeCN}$ and $3 \mathrm{ml}$ of $80 \% \mathrm{MeCN}$. 
34| Collect the $80 \%$ MeCN fraction and evaporate MeCN under a stream of nitrogen in a hood.

35| Freeze-dry the sample.

PAUSE POINT Permethylated glycans are stable for at least several months when stored at $-20{ }^{\circ} \mathrm{C}$.

\section{Preparation of glycans for MALDI-TOF-MS analysis}

36| Analyze permethylated glycans using the DHB matrix (option A) and desialylated native N-glycans isolated from gel-separated glycoproteins and purified glycans using a non-porous graphitized carbon mini-column using the THAP monohydrate matrix (option B) ${ }^{44}$. The THAP monohydrate matrix gives better results than the DHB matrix for sialylated and native glycans, especially when you work on small amounts ${ }^{45}$.

(A) Preparation of permethylated glycans for MALDI-TOF-MS

(i) Dissolve permethylated glycans in a methanol/water $(1: 1 ; \mathrm{vol} / \mathrm{vol})$ solution to obtain a concentration of $10 \mathrm{pmol} \mu \mathrm{l}^{-1}$.

(ii) Mix $1 \mu \mathrm{l}$ of the solution with $1 \mu \mathrm{l}$ of freshly made DHB matrix solution (see REAGENT SETUP) directly on to the MALDI target.

(iii) Allow the mixture to dry at room temperature.

(iv) Add $0.5 \mu$ l of ethanol solution (see REAGENT SETUP).

(v) Allow the mixture to dry at room temperature.

$\triangle$ CRITICAL STEP Recrystallization of the sample spot with ethanol promotes the formation of small crystals and is crucial for obtaining maximum sensitivity and spot-to-spot reproducibility. Care must be taken to prevent ethanol from spreading the sample over a larger area.

(B) Preparation of desialylated N-glycans released from gel-separated proteins for MALDI-TOF-MS

(i) Dissolve desialylated glycans in $10 \mu \mathrm{l}$ of water.

(ii) Mix $1 \mu \mathrm{l}$ with $1 \mu \mathrm{l}$ of freshly made THAP matrix solution (see REAGENT SETUP) directly on to the MALDI target.

$\triangle$ CRITICAL STEP The THAP matrix must be prepared just before use.

(iii) Allow the mixture to dry at room temperature.

(iv) Add $1 \mu$ l of freshly made ethanol solution (see REAGENT SETUP) ${ }^{45}$.

(v) Allow the mixture to dry at room temperature.

\section{Acquisition of MALDI-TOF-MS spectra}

37| Acquire the spectra by submitting each spot to multiple laser shots (100-500) over a range of $m / z=1,000-10,000$ for permethylated N-glycans, $m / z=300-10,000$ for permethylated 0 -glycans or $m / z=900-7,000$ for native $\mathrm{N}$-glycans. The laser spot should be moved to different areas of the target during acquisition, and spectra should be averaged until a satisfactory signal-to-noise ratio is obtained.

\section{Assignments of molecular ions observed in MALDI-TOF-MS spectra}

38 Calculate $[\mathrm{M}+\mathrm{Na}]^{+}$values by adding the sum of the residue masses and the sum of the sodiated reducing and nonreducing end increments (Table 1 ). The object of this exercise is to match calculated masses from Table 1 with the experimental masses to obtain the composition of the glycan. For example, the $\mathrm{m} / \mathrm{z}$ of a biantennary disialylated N-glycan is $2,792(2 \times 361.17+5 \times 204.09+4 \times 245.12+15.02+31.01+22.98)$. For 0 -glycans it has to be kept in mind that they are reduced with $\mathrm{NaBH}_{4}$ during the release of 0 -glycans from the peptidic chain. Therefore, $[\mathrm{M}+\mathrm{Na}]^{+}$values for 0 -glycans are obtained by adding the sum of the residue masses and the sum of sodiated non-reducing and reduced reducing end increments. For example, the $\mathrm{m} / \mathrm{z}$ of a glycan linked 0-glycosidically to Ser and Thr residues that has been released from the glycoproteins/ glycopeptides in the reduced form containing GalNAc-ol and with the following composition ( $\mathrm{NeuAc}_{1} \mathrm{Hex}_{1} \mathrm{HexNAc-ol)}$ is 895 $(361.17+204.09+245.12+15.02+47.05+22.98)$. This procedure can also be carried out with a computer using either in-house software or tools that are available on the Internet. For example, GlycoMod (http://www.expasy.ch/tools/glycomod/) is a web-based tool that can find all possible compositions of a glycan from its determined mass ${ }^{46}$. The program can be used to predict the composition of any glycoprotein-derived oligosaccharide.

\section{Nano-ESI-MS-MS of permethylated glycans}

39| Dissolve derivatized glycans in a solution of $80 \%$ methanol; $1 \%$ acetic acid can be added to promote formation of protonated adducts ${ }^{28}$.

40| Load $4 \mu$ into a gold-coated 'medium-length' borosilicate capillary.

41| Optimize the sprayer potential to achieve maximum sensitivity.

42 Record the conventional mass spectra: the number of scans required depends on the sample concentration and the resulting signal-to-noise ratio. 
PROTOCOL

43 Record MS/MS spectra over the range $m / z=100-3,000$. Collision energies depend on the type of molecular ion $\left([\mathrm{M}+2 \mathrm{Na}]^{2+}, 50-80 \mathrm{~V} ;[\mathrm{M}+2 \mathrm{H}]^{2+}, 15-30 \mathrm{~V}\right)$ and on the size of the carbohydrate. The number of scans required depends on the sample concentration and the resulting signal-to-noise ratio. The positive ion electrospray mass spectrum of glycans can be very variable, depending on the concentration of various cations in the solvent and on the cone voltage ${ }^{29}$.

\section{Preparation of PMAAs}

44| Dissolve permethylated glycans in $300 \mu \mathrm{l}$ of 4 M TFA in a glass tube.

45| Incubate at $100{ }^{\circ} \mathrm{C}$ for $4 \mathrm{~h}$.

46| Dry down the sample under a stream of nitrogen in a hood.

PAUSE POINT Dried samples are stable for at least several months when stored at $-20{ }^{\circ} \mathrm{C}$.

47| Add $200 \mu$ l of reduction solution (see REAGENT SETUP).

48| Leave at room temperature overnight.

49| Stop the reaction by adding acetic acid dropwise until no fizzing is observed (approximately three drops).

50| Dry down the sample under a stream of nitrogen in a hood.

51| Remove borate salts by repeated evaporation with methanol containing $5 \%$ acetic acid $(5 \times 500 \mu \mathrm{l})$ under a stream of nitrogen in a hood.

52| Evaporate the mixture to dryness.

$\triangle$ CRITICAL STEP It is important that the sample is completely dry before beginning the peracetylation reaction.

53| Add $20 \mu$ of pyridine and $200 \mu$ of acetic anhydride.

54 Incubate at $100{ }^{\circ} \mathrm{C}$ for $2 \mathrm{~h}$.

55 Evaporate the mixture to dryness under a stream of nitrogen in a hood.

PAUSE POINT Dried samples are stable for at least several months when stored at $-20{ }^{\circ} \mathrm{C}$.

56| Add $400 \mu \mathrm{l}$ of chloroform and $1 \mathrm{ml}$ of water. Mix vigorously, and allow the mixture to settle into two layers.

57| Transfer the lower chloroform phase into a new glass tube.

58| Add $400 \mu$ l of chloroform into the first tube. Mix vigorously, and allow the mixture to settle into two layers.

59| Transfer the lower chloroform phase into the new glass tube.

60| Repeat Steps 58 and 59 once.

61| Wash the chloroform phase ten times into the new glass tube with 1 volume of water and discard aqueous phases.

62 Dry down the chloroform phase under a stream of nitrogen in a hood.

$\triangle$ CRITICAL STEP Do not leave the sample under a stream of nitrogen for a long time when the sample is dried. Some PMAAs such as permethylated fucose are very volatile. The sample should be left for approximately $30 \mathrm{~min}$.

PAUSE POINT PMAAs are stable for at least several months when stored at $-20^{\circ} \mathrm{C}$.

\section{Linkage analysis of PMAAs by GC-MS}

63| Inject the PMAAs dissolved in methanol.

64| Run the GC method (see EQUIPMENT SETUP).

\section{Interpretation of GC-MS data}

65| Use the retention time on the capillary GC column and the fragment ions observed in the EI-MS spectra to identify the different type of residues (Table 4).

\section{TIMING}

In-solution deglycosylation after denaturation of glycoproteins with SDS: $1 \mathrm{~d}$

In-solution deglycosylation after reduction and alkylation of glycoproteins: $1 \mathrm{~d}$ 
In-gel deglycosylation and extraction of N-glycans: $2 \mathrm{~d}$

$\mathrm{N}$-glycan purification using a non-porous graphitized carbon column: approximately $3 \mathrm{~h}$

$\mathrm{N}$-glycan purification using a Sep-Pak $\mathrm{C}_{18}$ column: approximately $20 \mathrm{~min}$

Reductive elimination and purification of 0-glycans: $2 \mathrm{~d}$

Exoglycosidase digestions on the MALDI target: $6 \mathrm{~h}$

Exoglycosidase digestions in solution: $2 \mathrm{~d}$ for each enzyme

Permethylation: $2 \mathrm{~h}$

Purification of permethylated glycans using Sep-Pak $C_{18}$ : approximately 20 min

Preparation of glycans for MALDI-TOF-MS: approximately $10 \mathrm{~min}$

Acquisition of MALDI-TOF-MS spectra: approximately $1 \mathrm{~min}$

Note: However, if samples give very low signals, acquisition of MALDI-TOF-MS spectra can require approximately $30 \mathrm{~min}$.

Nano-ESI-MS-MS of permethylated glycans: approximately 5 min

Preparation of PMAAs: $5 \mathrm{~d}$

Linkage analysis of PMAAs by GC-MS: $1 \mathrm{~h}$

\section{ANTICIPATED RESULTS}

Figure 1 is a summary of the experimental strategies we currently use in our laboratory for the determination of the structures of $\mathrm{N}$ - and $\mathrm{0}$-linked glycans of glycoproteins. Three methods for preparing $\mathrm{N}$-glycans are described. These experimental strategies, which allow important structural conclusions to be drawn on the basis of picomolar amounts of components, are based on derivatization, chemical hydrolysis, exoglycosidase digestions, MALDI-TOF-MS, nano-ESI-MS-MS and GC-MS. In Figure 8, we present a MALDI-TOF-MS spectrum of permethylated N-glycans isolated from human serum. We have performed the protocol described in Figure 1a on $20 \mu \mathrm{l}$ of human serum. After denaturation of proteins with SDS, N-glycans are released using PNGase $\mathrm{F}$ and purified from $\mathrm{N}$-deglycosylated proteins using a non-porous graphitized carbon column (see Step 2A). An aliquot of purified $\mathrm{N}$-glycans (25\%) is permethylated, purified on a Sep-Pak $\mathrm{C}_{18}$ and analyzed using MALDI-TOF-MS (Fig. 8). The putative major structure assignments are based on molecular weight and knowledge of $\mathrm{N}$-glycan biosynthesis. From their $\mathrm{m} / \mathrm{z}$ ratio, monosaccharide composition in terms of Hex, dHex, NeuAc and HexNAc of each PNGase F-released oligosaccharide has been determined and is summarized in Table 5.

In most cases, however, additional experiments are necessary to assign the structures unambiguously. First, permethylated glycans observed in the MALDI-TOF spectrum are subjected to nano-ESI-MS-MS experiments to assist in sequence assignment. When analyzed using this system, permethylated glycans form preferentially sodiated molecular adducts in addition to protonated molecular adducts. Both types of molecular species produced this way can be subjected to CID to study their fragmentations using MS/MS. Even under low collision energy (typically $20 \mathrm{eV}$ ), $[\mathrm{M}+\mathrm{H}]^{+}$ions from permethylated glycans fragment very easily and glycosidic cleavages are prominent ${ }^{28}$. The fragments originating from both the reducing and the non-reducing ends of the glycan yield information on sequence and branching. Here, we show an example of a nano-ESI-MS-MS

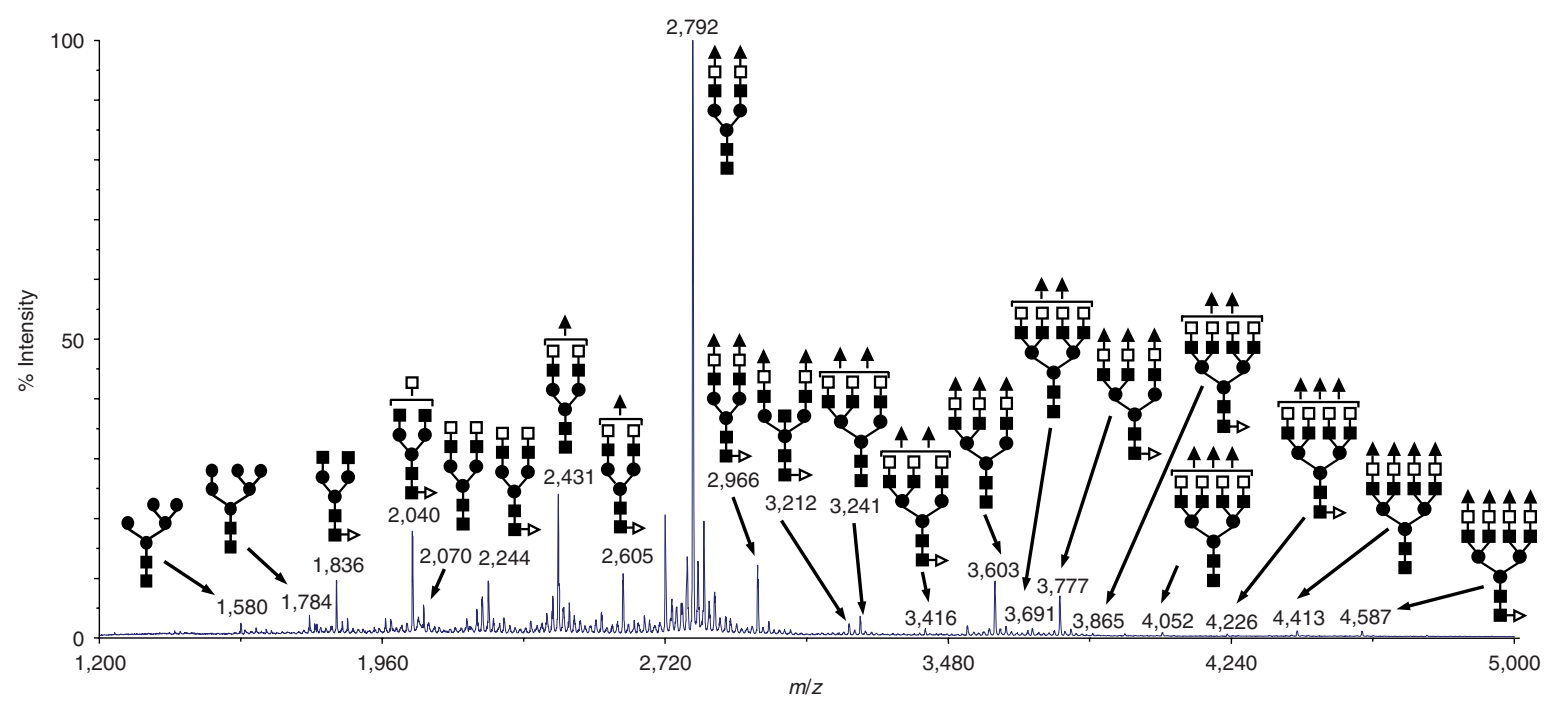

Figure 8 | Matrix-assisted laser desorption/ionization time of flight (MALDI-TOF) mass spectrum of permethylated N-glycans derived from $20 \mu$ l of human serum. One-quarter of the peptide N-glycosidase F (PNGase F)-released N-glycans were permethylated, purified on Sep-Pack $\mathrm{C}_{18}$ and analyzed using MALDI-TOF-MS. Only the structures of the major $\mathrm{N}$-glycans are given. A minor portion of the mono-fucosylated glycans carries fucose on an antenna rather than the core. Symbols: open square, galactose; closed square, $\mathrm{N}$-acetylglucosamine; open triangle, fucose; closed triangle, $\mathrm{N}$-acetyl-neuraminic acid; closed circle, mannose. 
spectrum of the precursor ion $[\mathrm{M}+2 \mathrm{H}]^{2+}$ of the permethylated $\mathrm{N}$-glycan (NeuAcFucHex ${ }_{5} \mathrm{HexNAc}_{4}$ ) observed in the MALDI-TOF spectrum (Fig. 9). This permethylated glycan was analyzed to gain more information on the antennae and to determine whether the core was fucosylated. The diagnostic ions at $\mathrm{m} / z 376$ (NeuAc) and 825 (NeuAc-Hex-HexNAc) are consistent with the antenna NeuAc-Hex-HexNAc as cleavage at the HexNAc residue is a favored event. The other diagnostic ion at $m / z 464$ is consistent with the antenna Hex-HexNAc. These ions at $m / z 376,464$ and 825 , together with the absence of ions at $m / z 638$ (Hex-[Fuc]-HexNAc) and 999 (NeuAc-Hex[Fuc]-HexNAc), suggest that the majority of the fucose residue is on the core of the glycan.

Second, permethylated PNGase F-released N-glycans from human serum are hydrolyzed and analyzed as their PMAA derivatives using GC-MS. The data presented in Table 4 confirm the MALDI-TOF-MS and nano-ESI-MS-MS data and give further information about $\mathrm{N}$-glycan structures. For example, comparison of the relative abundance of the 2-linked Man with 2,4-linked Man and 2,6-linked Man indicates that biantennary structures are more abundant than tri- and/or tetraantennary structures. The relative abundance of 4,6-linked GlcNAc confirms that the majority of $\mathrm{N}$-glycans are core-fucosylated. The presence of 3,4-linked GlcNAc suggests that some antennae are $\alpha 3$-fucosylated. The presence of bisected complex structures is indicated by 3,4,6-linked Man. Figure 7 illustrates the primary fragments obtained in EI-MS of the most common PMAAs obtained from $\mathrm{N}$-glycans, which are very useful in interpreting data. The primary fragments obtained in EI-MS of the other PMAAs can be obtained online (http://www.ccrc.uga.edu/specdb/ms/pmaa/).

Third, these experiments can be complemented by exoglycosidase digestions that define the anomeric configurations and confirm tentative sequences. $\mathrm{N}$-glycans released by PNGase $\mathrm{F}$ were subjected to digestion with $\alpha$-sialidase, $\beta$-galactosidase and $\beta$-N-acetyl-glucosaminidase and aliquots were taken after each digestion, permethylated and examined by MALDI-TOF-MS after reverse-phase Sep-Pak $C_{18}$ purification (Fig. 10). After neuraminidase treatment, the MALDI-TOF-MS data indicated that, as expected, all sialylated components previously described were converted to other compounds of reduced molecular weight consistent with the loss of one, two, three or four sialic acid residues. The $[\mathrm{M}+\mathrm{Na}]^{+}$ions provide evidence for this change (Fig. 10a). Thus, the NeuAc residues are in normal $\alpha$-linkages. Comparison of linkage data before and after sialidase treatment indicated that removal of terminal $\alpha$-NeuAc residues is accompanied by the loss of the 3 - and 6 -linked Gal (Table 4) and that there is a concomitant increase of terminal Gal, indicating that sialic acid residues were mainly attached to the 6-position of Gal residues. After $\alpha$-galactosidase treatment, the MALDI-TOF-MS spectrum of the N-glycans (Fig. 10b) was characterized by the presence of eight molecular ions at $m / z$ 1,580 $\left(\mathrm{Hex}_{5} \mathrm{HexNAc}_{2}\right), 1,662\left(\mathrm{Hex}_{3} \mathrm{HexNAc}_{4}\right), 1,784\left(\mathrm{Hex}_{6} \mathrm{HexNAc}_{2}\right), 1,836\left(\mathrm{Fuc}_{1} \mathrm{Hex}_{3}\right.$ $\left.\mathrm{HexNAc}_{4}\right), 1,908\left(\mathrm{Hex}_{3} \mathrm{HexNAc}_{5}\right), 2,082\left(\mathrm{Fuc}_{1} \mathrm{Hex}_{3} \mathrm{HexNAc}_{5}\right), 2,154\left(\mathrm{Hex}_{3} \mathrm{HexNAc}_{6}\right)$ and 2,328 (Fuc $\left.\mathrm{Hex}_{3} \mathrm{HexNAc}_{6}\right)$. Therefore, the $\mathrm{N}$-glycans were efficiently de-galactosylated, indicating that the Gal residues were in normal â-linkages. After $\beta$-N-acetylglucosaminidase treatment (Fig. 10c), the $[\mathrm{M}+\mathrm{Na}]^{+}$ions at $\mathrm{m} / z$ 1,662 $\left(\mathrm{Hex}_{3} \mathrm{HexNAc}_{4}\right), 1,908\left(\mathrm{Hex}_{3} \mathrm{HexNAc}_{5}\right), 2,154\left(\mathrm{Hex}_{3} \mathrm{HexNAc}_{6}\right)$ and 2,328 (Fuc ${ }_{1} \mathrm{Hex}_{3} \mathrm{HexNAc}_{6}$ ) disappeared, concomitant with the appearance of two new ions at $\mathrm{m} / z$ 1,171 and 1,345, which

\footnotetext{
Figure 9 | Tandem electrospray mass spectrometry of permethylated N-glycan observed at $m / z$ 2,605 in the matrix-assisted laser desorption-ionization time of flight (MALDI-TOF) mass spectrum. The doubly charged ion at $m / z 1,292.8$, corresponding to $m / z 2,605$ (NeuAcFucHex ${ }_{5} \mathrm{HexNAc}_{4}$ ), was selected for collisional activation. Assignments of the fragment ions are shown on the schematics. Symbols: open square, galactose; closed square, $\mathrm{N}$-acetylglucosamine; open triangle, fucose; closed triangle, $\mathrm{N}$-acetyl-neuraminic acid; closed circle, mannose.
}

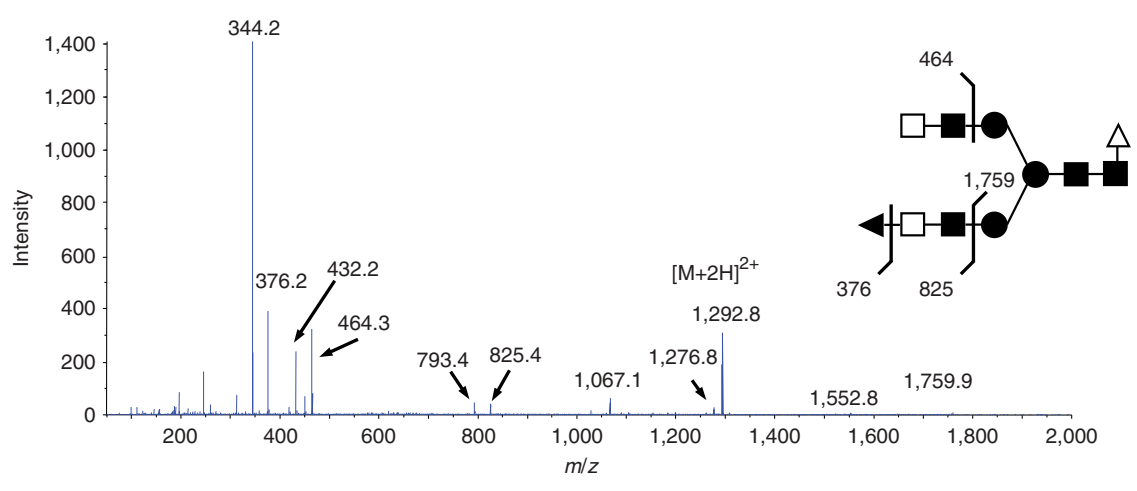



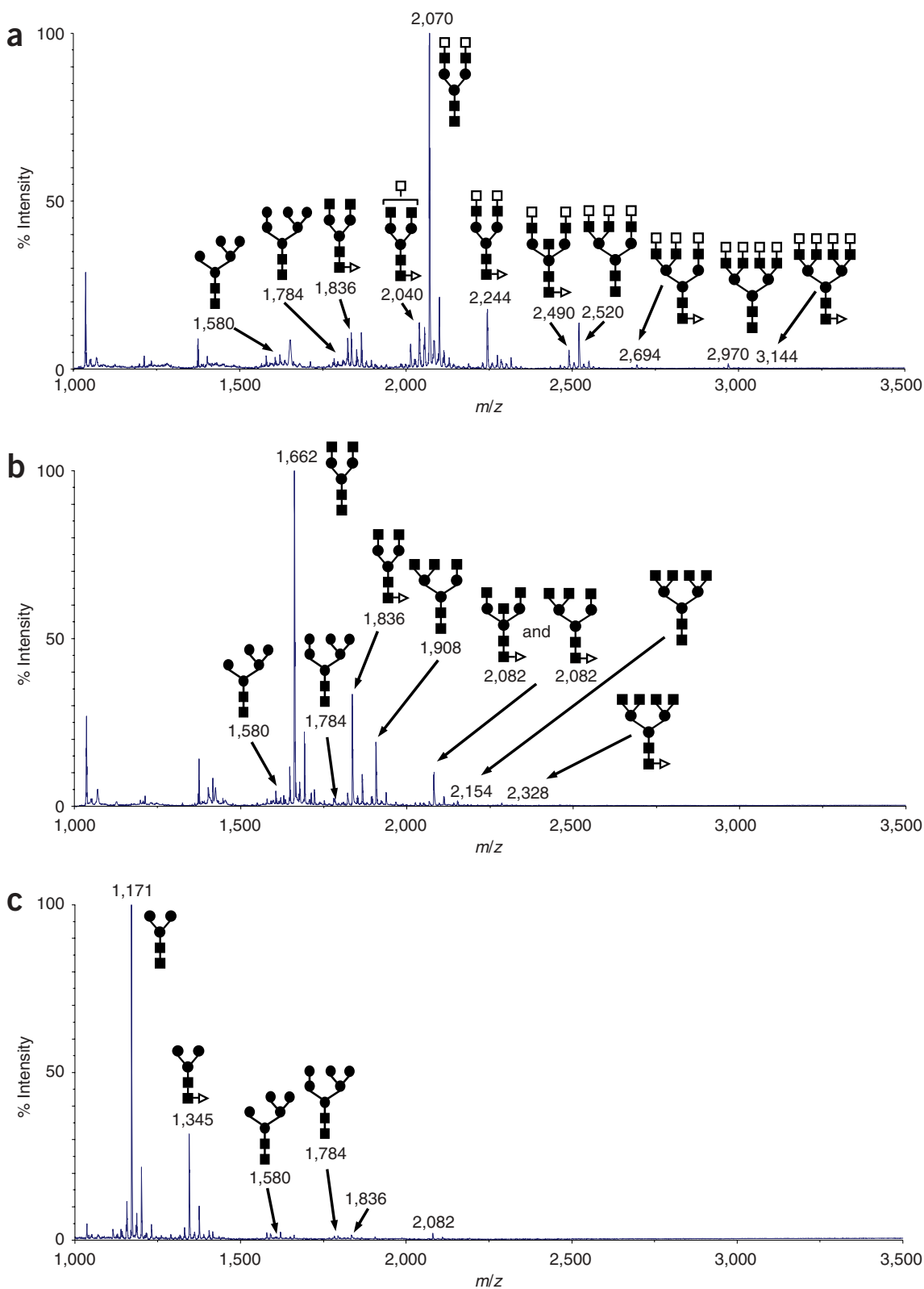

Figure 10 | Positive matrix-assisted laser desorption-ionization time of flight (MALDI-TOF) mass spectra of permethylated N-glycans from human serum after (a) $\alpha$-sialidase digestion, (b) $\beta$-galactosidase digestion and (c) $\beta$-N-acetylhexosaminidase digestion. The released glycans $(50 \%)$ from human serum (20 $\mu$ l) were sequentially digested with $\alpha$-sialidase, $\beta$-galactosidase, and $\beta$ - $N$-acetylhexosaminidase. Aliquots were taken after each digestion, permethylated and analyzed by MALDI-TOF-MS following Sep-Pak $\mathrm{C}_{18}$ purification. Symbols: open square, galactose; closed square, $\mathrm{N}$-acetylglucosamine; open triangle, fucose; closed triangle, $\mathrm{N}$-acetyl-neuraminic acid; closed circle, mannose.

correspond respectively to $\mathrm{Hex}_{3} \mathrm{HexNAc}_{2}$ and $\mathrm{Fuc}_{1} \mathrm{Hex}_{3} \mathrm{HexNAc}_{2}$. The signals at $m / z$ 1,580 $\left(\mathrm{Hex}_{5} \mathrm{HexNAc}_{2}\right)$ and 1,784 $\left(\mathrm{Hex}_{6} \mathrm{Hex}_{-}\right.$ $\mathrm{NAc}_{2}$ ) were unaffected by the above exoglycosidase digestions, a result that is consistent with the assignment of high mannose structure to these ions.

ACKNOWLEDGMENTS This research was supported by the Centre National de la Recherche Scientifique (Unité Mixte de Recherche CNRS/USTL 8576), the Ministère de la Recherche et de l'Enseignement Supérieur. The mass spectrometry facility used in this study was funded by the European Community (FEDER), the Région Nord-Pas de Calais (France) and the Université des Sciences et Technologies de Lille.

COMPETING INTERESTS STATEMENT The authors declare no competing financial interests.
Published online at http://www.natureprotocols.com

Reprints and permissions information is available online at http://npg.nature.com/ reprintsandpermissions

1. Ohtsubo, K. \& Marth, J.D. Glycosylation in cellular mechanisms of health and disease. Cell 126, 855-867 (2006).

2. Varki, A. Biological roles of oligosaccharides: all of the theories are correct. Glycobiology 3, 97-130 (1993).

3. Hellerqvist, C.G. Linkage analysis using Lindberg method. Methods Enzymol. 193 , 554-573 (1990). 
4. Dell, A. FAB mass spectrometry of carbohydrates. Adv. Carbohydr. Chem. Biochem. 45, 19-72 (1987).

5. Faid, V., Evjen, G., Tollersrud, 0.K., Michaslki, J.C. \& Morelle, W. Site specific glycosylation analysis of the bovine lysosomal alpha mannosidase. Glycobiology 16, 440-461 (2006).

6. Morelle, W. et al. Galactomannoproteins of Aspergillus fumigatus. Eukaryot. cell 4, 1308-1316 (2005).

7. Morelle, W., Jimenez, J.C., Cieniewski-Bernard, C., Dei-Cas, E. \& Michalski, J.C. Characterization of the N-linked glycans of Giardia intestinalis. Glycobiology 15, 549-559 (2005).

8. Morelle, W., Donadio, S., Ronin, C. \& Michalski, J.C. Characterization of N-glycans of recombinant human thyrotropin using mass spectrometry. Rapid Commun. Mass Spectrom. 20, 331-345 (2006).

9. Morelle, W. et al. Mass spectrometric approach for screening modifications of total serum N-glycome in human diseases: application to cirrhosis. Glycobiology, 16, 281-293 (2006).

10. Faid, V., Chirat, F., Seta, N., Foulquier, F. \& Morelle, W. A rapid mass spectrometric strategy for the characterization of $\mathrm{N}$ - and 0 -glycan chains in the diagnosis of defects in glycan biosynthesis. Proteomics 7, 1800-1813 (2007).

11. Tarentino, A.L. \& Plummer, T.H. Enzymatic deglycosylation of asparagine-linked glycans: purification, properties, and specificity of oligosaccharide-cleaving enzymes from Flavobacterium meningosepticum. Methods Enzymol. 230, 44-57 (1994).

12. Tretter, V., Altmann, F. \& Marz, L. Peptide-N4-( $N$-acetyl- $\beta$-glucosaminyl) asparagine amidase $F$ cannot release glycans with fucose attached $\alpha 1-3$ to the asparagine linked $\mathrm{N}$-acetylglucosamine residue. Eur. J. Biochem. 199, 647-652 (1991).

13. Carlson, D.M. Structures and immunochemical properties of oligosaccharides isolated from pig submaxillary mucins. J. Biol. Chem. 243, 616-626 (1968).

14. Küster, B., Wheeler, S.F., Hunter, A.P., Dwek, R.A. \& Harvey, D.J. Sequencing of $\mathrm{N}$-linked oligosaccharides directly from protein gels: in-gel deglycosylation followed by matrix-assisted laser desorption/ionization mass spectrometry and normal-phase high-performance liquid chromatography. Anal. Biochem. 250, 82-101 (1997).

15. Wheeler, S.F. \& Harvey, D.J. Extension of the in-gel release method for structural analysis of neutral and sialylated $\mathrm{N}$-linked glycans to the analysis of sulfated glycans: application to the glycans from bovine thyroid-stimulating hormone. Anal. Biochem. 296, 92-100 (2001).

16. Patel, T. et al. Use of hydrazine to release in intact and unreduced form both $\mathrm{N}$ - and 0-linked oligosaccharides from glycoproteins. Biochemistry 32, 679-693 (1993).

17. Huang, Y., Mechref, Y. \& Novotny, M.V. Microscale nonreductive release of 0 -linked glycans for subsequent analysis through MALDI mass spectrometry and capillary electrophoresis. Anal. Chem. 73, 6063-6069 (2001).

18. Huang, Y., Konse, T., Mechref, Y. \& Novotny, M.V. Matrix-assisted laser desorption/ ionization mass spectrometry compatible beta-elimination of 0 -linked oligosaccharides. Rapid Commun. Mass Spectrom. 16, 1199-1204 (2002).

19. Taylor, A.M., Holst, 0 . \& Thomas-0ates, J. Mass spectrometric profiling of 0 -linked glycans released directly from glycoproteins in gels using in-gel reductive $\beta$-elimination. Proteomics 5, 2936-2946 (2006).

20. Colangelo, J. \& Orlando, R. On-target exoglycosidase digestions/MALDI-MS for determining the primary structures of carbohydrate chains. Anal. Chem. 71, 1479-1482 (1999).

21. Zaia, J. Mass spectrometry of oligosaccharides. Mass Spectrom. Rev. 23, 161-227 (2004).

22. Morelle, W., Canis, K., Chirat, F., Faid, V. \& Michalski, J.C. The use of mass spectrometry for the proteomic analysis of glycosylation. Proteomics $\mathbf{6}$, 3993-4015 (2006)

23. Powell, A.K. \& Harvey, D.J. Stabilization of sialic acids in $\mathrm{N}$-linked oligosaccharides and gangliosides for analysis by positive ion matrix-assisted laser desorption/ionization mass spectrometry. Rapid Commun. Mass Spectrom. 10, 1027-1032 (1996)

24. Ciucanu, I. \& Kerek, F. A simple and rapid method for the permethylation of carbohydrates. Carbohydr. Res. 131, 209-217 (1984).
25. Ciucanu, I. \& Costello, C.E. Elimination of oxidative degradation during the per-0methylation of carbohydrates. J. Am. Chem. Soc. 125, 16213-16219 (2003).

26. Kang, P., Mechref, Y., Klouckova, I. \& Novotny, M.V. Solid-phase permethylation of glycans for massspectrometric analysis. Rapid Commun. Mass Spectrom. 19 3421-3428 (2005).

27. Wong, N.K. et al. Characterization of the oligosaccharides associated with the human ovarian tumor marker CA125. J. Biol. Chem. 278, 28619-28634 (2003).

28. Morelle, W., Faid, V. \& Michalski, J.C. Structural analysis of permethylated oligosaccharides using electrospray ionization quadrupole time-of-flight tandem mass spectrometry and deutero-reduction. Rapid Commun. Mass Spectrom. 18, 2451-2464 (2004).

29. Harvey, D.J. Collision-induced fragmentation of underivatized N-linked carbohydrates ionized by electrospray. J. Mass Spectrom. 35, 1178-1190 (2000).

30. Morelle, W. \& Michalski, J.C. The mass spectrometric analysis of glycoproteins and their glycan structures. Curr. Anal. Chem. 1, 27-55 (2005).

31. Domon, B. \& Costello, C.E. A systematic nomenclature for carbohydrate fragmentations in FAB-MS/MS spectra of glycoconjugates. Glycoconj. J. 5, 397-409 (1988).

32. Viseux, N., de Hoffmann, E. \& Domon, B. Structural assignment of permethylated oligosaccharide subunits using sequential tandem mass spectrometry. Anal. Chem. 70, 4951-4959 (1998).

33. Jacob, G.S. \& Scudder, P. Glycosidases in structural analysis. Methods Enzymol. 230, 280-299 (1994).

34. Geyer, H., Schmitt, S., Wuhrer, M. \& Geyer, R. Structural analysis of glycoconjugates by on-target enzymatic digestion and MALDI-TOF-MS. Anal. Chem. 71, 476-482 (1999).

35. Mechref, Y. \& Novotny, M.V. Mass spectrometric mapping and sequencing of Nlinked oligosaccharides derived from submicrogram amounts of glycoproteins. Anal. Chem. 70, 455-463 (1998).

36. Albersheim, P., Nevins, D.J., English, P.D. \& Karr, A. A method for the analysis of sugars in plant cell wall polysaccharides by gas-liquid chromatography. Carbohydr. Res. 5, 340-345 (1967).

37. Geyer, R. \& Geyer, H. Saccharide linkage analysis using methylation and other techniques. Methods Enzymol. 230, 86-108 (1994).

38. Hellerqvist, C.G. Linkage analysis using Lindberg method. Methods Enzymol. 193 554-573 (1990).

39. Young, N.M. et al. Structure of the N-linked glycan present on multiple glycoproteins in the Gram-negative bacterium, Campylobacter jejuni. J. Biol. Chem. 277, 42530-42539 (2002).

40. Liu, X. et al. Mass spectrometry-based glycomics strategy for exploring $\mathrm{N}$-linked glycosylation in eukaryotes and bacteria. Anal. Chem. 78, 6081-6087 (2006).

41. Hakomori, S. A rapid permethylation of glycolipid, and polysaccharide catalyzed by methylsulfinyl carbanion in dimethyl sulfoxide. J. Biochem. (Tokyo) 55, 205-208 (1964).

42. Fournet, B., Strecker, G., Leroy, Y. \& Montreuil, J. Gas-liquid chromatography and mass spectrometry of methylated and acetylated methyl glycosides. Application to the structural analysis of glycoprotein glycans. Anal. Biochem. 116, 489-502 (1981).

43. Packer, N.H., Lawson, M.A., Jardine, D.R. \& Redmond, J.W. A general approach to desalting oligosaccharides released from glycoproteins. Glycoconj. J. 15, 737-747 (1998).

44. Papac, D.I., Wong, A. \& Jones, A.J.S. Analysis of acidic oligosaccharides and glycopeptides by matrix-assisted laser desorption/ionization time-of-flight mass spectrometry. Anal. Chem. 68, 3215-3223 (1996).

45. Sagi, D., Kienz, P., Denecke, J., Marquardt, T. \& Peter-Katalinic, J. Glycoproteomics of N-glycosylation by in-gel deglycosylation and matrix-assisted laser desorption/ionisation-time of flight mass spectrometry mapping: application to congenital disorders of glycosylation. Proteomics 5, 2689-2701 (2005).

46. Cooper, C.A., Gasteiger, E. \& Packer, N.H. GlycoMod-a software tool for determining glycosylation compositions from mass spectrometric data. Proteomics 1, 340-349 (2001). 